\title{
QUEEN'S
UNIVERSITY
BELFAST
}

\section{Metallosupramolecular grid complexes: towards nanostructured materials with high-tech applications}

Hardy, J. G. (2013). Metallosupramolecular grid complexes: towards nanostructured materials with high-tech applications. Chemical Society Reviews, 42(19), 7881-7899. https://doi.org/10.1039/c3cs60061k

Published in:

Chemical Society Reviews

Document Version:

Peer reviewed version

Queen's University Belfast - Research Portal:

Link to publication record in Queen's University Belfast Research Portal

Publisher rights

Copyright 2013 The Authors

\section{General rights}

Copyright for the publications made accessible via the Queen's University Belfast Research Portal is retained by the author(s) and / or other copyright owners and it is a condition of accessing these publications that users recognise and abide by the legal requirements associated with these rights.

Take down policy

The Research Portal is Queen's institutional repository that provides access to Queen's research output. Every effort has been made to ensure that content in the Research Portal does not infringe any person's rights, or applicable UK laws. If you discover content in the Research Portal that you believe breaches copyright or violates any law, please contact openaccess@qub.ac.uk. 


\title{
Chemical Society Reviews
}

Cite this: DOI: 10.1039/c0xx00000x

www.rsc.org/csr

REVIEW ARTICLE

\section{Metallosupramolecular grid complexes: towards nanostructured materials with high-tech applications}

\author{
John G. Hardy $* a, b, c$ \\ Received (in $X X X, X X X)$ ) $X$ th $X X X X X X X X X 20 X X$, Accepted $X t h X X X X X X X X X 20 X X$ \\ DOI: 10.1039/b000000x
}

Metallosupramolecular grid complexes (hereafter referred to as metallogrids) are well-defined oligonuclear metal ion complexes involving essentially planar arrays of the metal ions sited at the points of intersection of square or rectangular metallogrids and possess a variety of interesting optical, electronic, magnetic and supramolecular properties. Herein I aim to give the reader an overview of the synthesis, properties and potential for a variety of high-tech applications of metallogrids.

\section{Novel Properties}

- Electronic

- Magnetic

- Optical

- Supramolecular

- Stimuli Responsive

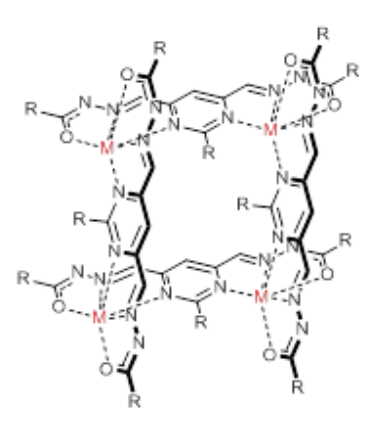

Technological applications Nanoscale Electronics/Spintronics

Biological applications Diagnostics/Therapeutics 


\section{Cite this: DOI: $10.1039 / \mathrm{c0xx00000x}$}

www.rsc.org/csr

REVIEW ARTICLE

\section{Introduction}

Metal-ion-directed assembly is a common feature of the creation of functional supramolecular entities of both natural ${ }^{1-7}$ and synthetic ${ }^{8-19}$ origins. There are well-defined entities composed of a discrete number of ligands and metal ions, examples of which include, in not necessarily mutually exclusive categories, metalloproteins, ${ }^{20,21}$ helical structures (e.g. G-quartets ${ }^{1,2}$ and helicates, ${ }^{8-10,22-29}$ grids, ${ }^{8,11,30-34}$ 5 racks, ${ }^{35,36}$ squares/rectangles, ${ }^{8,11,16,37-50}$ metallamacrocycles, ${ }^{17,}, 48,51-53$ capsules ${ }^{52-55}$ and cages, ${ }^{16,56-59}$ and moreover, entities composed of a non-discrete number of ligands and metal ions, such as metallosupramolecular polymers ${ }^{60-68}$ (see Fig. 1 for examples).

The term "metallogrid" is applied to oligonuclear metal ion complexes in which the array of metal ions is essentially planar and ideally each metal ion can be considered to define a junction in a square or rectangular grid. ${ }^{30-34,36}$ The simplest and indeed the most commonly encountered case is that of a $2 \times 2$ array, to which the terms "metallosquare", "metallorectangle" or "metallamacrocycle" might equally well 10 be applied. In fact, there is a domain of coordination chemistry concerning metallosquares ${ }^{52,53}$ that has been systematically developed on the basis of appropriate ligand design but which is excluded from the present considerations since the ligands involved in bridging the metal ions do not act as chelates, so that the design principle involved is different, although there are cases where such a distinction is not possible. ${ }^{40,42-44,47,48,69}$ It may also be noted that there are many examples of tetranuclear complexes incorporating square $\mathrm{M}_{4}$ units formed by ligands for which such structures were not initially anticipated, ${ }^{70-73}$ and that a parallel has been drawn between an infinite metallogrid 15 and the two-dimensional arrays of complex cations found in the lattices of transition metal ion complexes of terpyridine and its derivatives in which the "terpyridine embrace", obviating direct bridging by chelation, can be discerned. ${ }^{74}$ In principle, such materials might also be suitable for the applications presently discussed.

The work usually considered to define the first metallogrid formed as a result of a deliberate ligand design is that of Youinou et al. ${ }^{75}$ involving the $\mathrm{Cu}(\mathrm{I})$ complex of the rigid ditopic ligand 3,6-bis(2'-pyridyl)-pyridazine (Fig. 2, ligand 1). The rigidity of the ligand means 20 that all four donor atoms cannot be bound to one metal ion, so that any one ligand molecule can only function as a bis(bidentate) species towards two metal ions, although it is quite clear in the solid state (Fig. 3) that there is considerable idealization involved in describing the ligand as truly planar, the coordination geometry as exactly tetrahedral and the $\mathrm{Cu}_{4}$ unit as constituting a true square, as the distortions involved are apparently dynamic in solution. The chemistry of systems of this type has been extensively developed by the Lehn ${ }^{33,34,76}$ and Thompson ${ }^{11,30,31,76,77}$ groups but certainly not by these alone. ${ }^{32,78}$ The optical, electronic, magnetic and supramolecular characteristics of 25 metallogrids have been explored in the solution and solid states, and the variety of possible applications proposed has stimulated continuing interest in these materials. $8,11,30,31,33,34,76,79,80$

This article is intended to give an overview of the general design principles for the preparation of metallogrids, their physicochemical/supramolecular properties, and finally their potential utility as nanostructured materials with high-tech applications.

\section{General design principles of metallogrid complexes}

30 The design principles exploited for the synthesis of the now very numerous known examples of metallogrid-forming ligands similar to ligands 1-12 (Fig. 2) have been considered in detail in earlier research papers and reviews, ${ }^{33,34,81}$ and readers with an avid interest in their crystal structures are directed to excellent reviews by Thompson and co-workers. ${ }^{30-32}$ In essence, for the common, simple cases of metal ions of tetrahedral, pentagonal bipyramidal or octahedral coordination geometry, the coordination spheres can be considered divisible into two orthogonal planes involving 2 and/or 3 donor atoms. If one ligand in which 2 or 3 donor atoms are or can become coplanar when a 35 metal ion is bound, then a second similar ligand must be bound with its donor atoms in an orthogonal plane. If the ligand structure is extended in the direction of the 1,2 or 1,3 donor atom vectors in such a way that bending to allow all donor atoms in adjacent bi- or tridentate sites to bind to one metal ion is impossible, metal ion binding to this ligand can give a linear array of metal ions composing a rack where each metal ion still has coordination sites available for occupancy by a multidentate ligand (see Fig. 1B). If a ligand of the original type is used for this purpose, then it must bind in a direction perpendicular to that of the rack. Continuation of this process can have various 40 consequences, but only the closed planar grid structure results in all donor atoms being coordinated, a situation which seems to explain why the grid is preferred over other possible oligomeric structures when the total number of donor atoms matches that of the total number of metal ion coordination sites. ${ }^{30,31,33,34}$ Note that in most known cases (the "norm") the grid is such that a layer of metal ions may be considered sandwiched between sheets of ligands, but it is also possible, for example with a ligand such as 11, ${ }^{82}$ to form "inverse grids" where the binding units of a given ligand alternate in their orientation relative to the metal ion plane. ${ }^{83,84} \mathrm{~A}$ very wide range of grid-forming 45 ligands conforming to the requirements above have been reported, for example, ligands 1-12. Clearly, it is possible to vary considerably not only the donor atom characteristics, but also the functionality of the ligand and indeed which metal ions are incorporated, each metal ion endowing the grid with some unique properties. Thus, the nature of the donor atoms, the denticity and size of the binding site, and the size of the chelate rings formed dictate the identity, number and position of the metal ions that are bound in the metallogrid, while the substituents may offer means to modify properties (luminescence, magnetism, electrochemistry) brought to the grid by the metal ion, to 50 control aggregation of the grids or to enable grafting of the grids to other substrates of interest (e.g. polymers). Symmetrical substitution 
of course has been preferred in order to minimise the isomeric complexity of the grids formed. Unsurprisingly, experience has shown that the assumptions underlying the basic principles outlined above are not inviolable, ${ }^{30-34}$ and there are various instances known where, for example, the polytopic ligands do not provide all the donor atoms bound to the metal ions ${ }^{85-88}$ or the grid is not the only closed oligomer formed ${ }^{82}$ but the simplest guidelines nonetheless remain useful.

5 Of the wide variety of grid-forming ligands now known, $30-34,81,89$ most incorporate nitrogen donor units forming five-membered chelate rings such as those of the bipyridine or terpyridine form (e.g. ligands $\mathbf{1}$ and $\mathbf{2}$ respectively), although significant numbers involve oxygen or sulphur-based donor sites (e.g. ligands 3,4 and 5), again with five-membered chelate rings preferred for maximum stability. Internal oxo groups of numerous ligands are particularly important as bridges between metal ion centres which enhance electronic and magnetic interactions. ${ }^{32}$ Also, a recent report (concerning ligand 4) shows that the embellishment of a basic N-donor grid-forming ligand with 10 hydroxymethyl substituents may control whether or not a grid is formed with a particular metal. ${ }^{90}$ Whilst metallogrids derived from ditopic bisterpyridine type ligands (e.g. ligand 2) have properties which serve to illustrate a variety of potential applications, ${ }^{33,34}$ such ligands are far more challenging to synthesise than isotypic ligands incorporating hydrazone or acylhydrazone moieties as metal binding sites (e.g. ligands 5 and 6). In fact, hydrazone-based ligands are the basis of by far the majority of currently known grid systems, ${ }^{30-34,91}$ this work forming but part of the very extensive and interesting coordination chemistry of such ligands. ${ }^{11,89,91,92}$ A particularly attractive feature of 15 acylhydrazone-based systems is that they are derived from acylhydrazines, which can be readily prepared from the immense variety of known carboxylic acids. For example, it is straightforward to prepare [2x2] metallogrids based on bis(acylhydrazone) derivatives of dialdehydes (such as 2-phenylpyrimidine-4,6-dialdehyde) ${ }^{93}$ that are soluble in polar (e.g. water) or non-polar (e.g. toluene) solvents depending on the carboxylic acid used to prepare the acylhydrazine (e.g. as in ligand 7). ${ }^{93,94}$

Metallogrids can most simply be prepared by the reaction of a preformed ligand and a source of labile metal ions in a suitable solvent ${ }^{30}$, $2031,33,34,95-97$ (e.g. ligands 1-12) and it has also proven possible to use mixtures of ligands, thereby allowing the formation of rectangular [m $\mathrm{x} \mathrm{n}$ ] grids). ${ }^{30,31,33,34}$ Furthermore, it is possible to form metallogrids from dynamic libraries of ligands, ${ }^{98}$ using "dynamic" acylhydrazone, hydrazone and imine species. As many large heteroaromatic ligands derived by imine or hydrazone condensations are of low solubility in all solvents, it has frequently proved more convenient to conduct a template synthesis from the components. ${ }^{93}$ It should be noted that many metallogrids have been characterised in the solid state only by X-ray crystallographic studies and the complicated solution equilibria 25 involved in their formation have not generally been studied in any detail. ${ }^{99,} 100$ As noted above, there are reasons to expect the grid structure

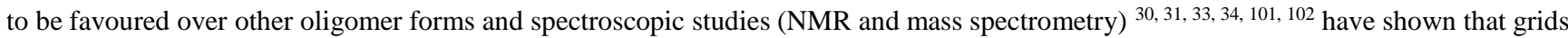
characterised in the solid state retain their structure in solution down to concentrations as low as $10^{-4} \mathrm{M}$, at least in solvents of only moderate polarity. Substitution on the ligand framework can have an important influence on the stability of a grid and, for example, $\mathrm{Cu}$ (II) grids formed from the 2-H-pyrimidine-based ligand $\mathbf{8}$ are markedly less stable than those formed from the 2-phenyl triazine-based ligand $\mathbf{9}$, ${ }^{100}$ 30 and other examples of this effect are known. ${ }^{33}$ While most known grids have been prepared from labile metal ions, the use of inert metal ions such as $\mathrm{Co}(\mathrm{III})$ and $\mathrm{Ru}(\mathrm{II})$ has enabled alternative syntheses based on the reaction of inert, $\mathrm{M}(\text { ligand })_{2}$ "corner" complexes with a labile metal ion to be used to provide heterometallic grid complexes. ${ }^{84,99,103-106}$ This approach has, however, only been applied to [2x2] grids. Heterobimetallic [2x2] grids can of course also be obtained by the use of unsymmetrical ligands ${ }^{87,107}$ and grids which are heterometallic in the sense that they contain both $\mathrm{Fe}(\mathrm{II})$ and $\mathrm{Fe}(\mathrm{III})$ have been considered of particular interest for information storage ${ }^{108}$, ${ }_{35} 109$ (redox chemistry of grids is considered more generally later in the review).

Use of the corner complex procedure is of particular interest because it is based on a "Coupe du Roi" analysis ${ }^{110}$ of the "normal" [2x2] grid structure. ${ }^{33,99}$ Thus, any corner unit is chiral and, within a given grid, opposite corners must be of the same chirality but opposite to that of the other corners, so that while a homometallic grid must be achiral, a trans- $\mathrm{M}^{6}{ }_{2} \mathrm{M}_{2}$ grid (and note that this includes the case where $\mathrm{M}$ and $\mathrm{M}$ ' are simply isotopes of the one metal) must be chiral and should form with complete enantioselectivity from an optically resolved 40 corner species provided that species does not readily racemise. ${ }^{33,99,103}$ This experiment has not actually been conducted, but a simple means to obtain an optically active grid is to add a substituent of one particular chirality to the ligand. Interestingly, this has been done for the ligand 11, designed to form "inverse" grids where all four corners in a given grid molecule have the same chirality. Thus, the presence of (+)-pinene units in $\mathbf{1 1}$ means that any corner unit has diastereomeric forms and thus that the grid may consist of two diastereomers, which in this case differ in energy such as to give a 95:5 equilibrium mixture from which the major species can be crystallised pure. ${ }^{82}$ Steric 45 effects, presumably the origin of these diastereomer differences, have been noted to play an important role generally in metallogrid formation, as shown, for example, in an investigation of grid formation by a variety of linear polymers (including poly(L-lactide), ${ }^{111}$ poly $(\varepsilon-$ caprolactone), ${ }^{112}$ and poly(ethylene glycol) ${ }^{113}$ having a grid-compatible ligand at one terminus (e.g. 12), the objective being to generate star polymers by metal ion $(\mathrm{Cu}(\mathrm{I}))$ complexation. Here, the molecular weight of the polymer is important, as those with molecular weights of ca. $10 \mathrm{kDa}$ did not form [2x2] metallogrid complexes (ascribed to unfavourable steric interactions between the ligands), whereas those 50 of lower molecular weight (of 2.5-6 kDa) readily formed [2x2] metallogrids. ${ }^{111}$ Similar observations, probably not exclusively due to steric effects, have been reported for families of ligands in which seemingly minor changes in the structures of the ligands (e.g. heterocycles within the ligand, or bulky groups at the termini) prevented metallogrid formation and led to the formation of other clusters. $30,31,33,34,90$, 101,114

There are certain ligands which have been specifically designed to facilitate the assembly of the resultant metallogrids into hierarchically 55 ordered structures in the solution or solid state, thereby imparting useful modifications to the properties to the metallogrids; I discuss these and their potential for high-tech applications ahead.

\section{Solution chemistry of metallogrids - responses to chemical stimuli}


Stimuli-responsive systems are of fundamental interest for technical and biomedical applications, and a variety of metallogrids responsive to both chemical and physical stimuli are known. ${ }^{60,61,115,116}$ The enhancement of ligand acidity resulting from coordination, for example, means that many metallogrids behave as weak acids. Thus, in solution, as chemical stimuli, protonation/deprotonation reactions can be used to modulate the optical properties of [2x2] Co(II) grids formed from ligands $\mathbf{1 3}$ or $\mathbf{1 4}$ (both depicted in Fig. 4), ${ }^{117}$ the redox properties 5 of [2x2] $\mathrm{Fe}$ (II) grids formed from ligand $\mathbf{1 3},{ }^{118}$ and the assembly/disassembly of [2x2] metallogrids formed from dynamic combinatorial libraries of ligand-forming components. ${ }^{98} \mathrm{Grids}$ in some cases are also sensitive to their environment, so that a change of solvent can result in transformations to other oligonuclear species. For example, [2x2] $\mathrm{Cu}$ (II) grids formed from ligand 15 (Fig. 4) convert to hexanuclear complexes (incorporating 6 ligands and 6 metal ions, with a hexagonal array of the metal ions) in response to a change in the solvent composition (from grid complexes in nitromethane to hexanuclear species in acetonitrile), ${ }^{119}$ and similarly, [2x2] Co(II) grids formed from 109 change from grid complexes in nitromethane to pincer-like complexes in acetonitrile (Fig. 5). ${ }^{120}$ Grids may undergo breakdown reactions in the presence of some ligands that favour mononuclear complexes, as well as in the presence of excess metal ions, such reactions show that although the grids are relatively stable, this stability is not in general such as to render them kinetically inert. The formation of the [4x4] $\mathrm{Pb}_{16}(\mathbf{1 6})_{8}$ metallogrids from ligand 16 (Fig. 4) has the interesting consequence that the ligand undergoes a major molecular movement from a helical form when free to an essentially linear, extended conformation in the grid. ${ }^{85}$ In the presence of excess Pb(II), the same grid 15 can be converted to isomeric $\mathrm{Pb}_{12}(\mathbf{1 6})_{4}$ species in which only four of the $\mathrm{Pb}(\mathrm{II})$ ions are bound to sites of two ligands. Similar behaviour can be observed for the [4x4] $\mathrm{Pb}$ (II) grid formed with ligand 17 (Fig. 4), where it has been shown that the tetramine "tren" can be used to strip $\mathrm{Pb}$ (II) from the $\mathrm{Pb}_{16}(\mathbf{1 7})_{8}$ grid and allow the extended ligand to return to a helical form, and that excess $\mathrm{Pb}$ (II) converts the grid into singly stranded "rack" complexes. ${ }^{121}$ Even a ligand as simple as thiocyanate (NCS") can serve, via transient coordination of Co(II), as a catalyst for a remarkable transformation of a [2x2] $\mathrm{Co}(\mathrm{II})_{2} \mathrm{Co}(\mathrm{III})_{2}$ grid derived from ligand 18 (Fig. 4) into a double-grid [2]-catenane (Fig. 20 6). ${ }^{122} \mathrm{In}[2 \times 2] \mathrm{Ni}$ (II) grids formed from ligand $\mathbf{1 9}$ (Fig. 4), the presence of both coordination sites on Ni(II) occupied by unidentate ligands and deprotonatable oxime-hydroxyl groups on the ligand means that basic conditions can be used to produce a dodecanuclear trimer of the original grid centred on an hydroxide ligand. ${ }^{123}$ The work preceding this development, ${ }^{87}$ incidentally, provides one of the few examples of a thorough thermodynamic analysis of equilibria in solution involving a grid-forming ligand.

Since both heteroaromatic ligands and many metal ions can be redox-active, electrochemical methods have been used in many instances 25 to convert a single grid into several distinct species with different redox potentials. ${ }^{30,31,33,34}$ The existence of multiple states for any given system is of course a key feature of a variety of possible applications, although even a grid in which the metal centres are electronically isolated from one another so that all metal-based redox events occur at essentially the same potential, might find use as a multi-electron source, especially for reactions with an included substrate. Redox processes (usually electrochemically reversible) of grids have been widely studied by voltammetric techniques ${ }^{30,31,33,34}$ and in certain instances, notably involving Co(II) and Fe(II) grids, ${ }^{30,31,33,34}$ chemical 30 oxidation (by atmospheric oxygen or, for example, reagents such as $\mathrm{Ce}(\mathrm{IV})^{93}$ and even $\mathrm{Cu}(\mathrm{II})^{124}$ ) have been conducted. In general, both oxidation and reduction processes are possible for any grid, but in the case of the [2x2] Co(II) grid formed from ligand 20 (Fig. 4 ), for example, the oxidation processes are electrochemically irreversible and ill-defined, and only the reduction processes occur reversibly, indicating that the grid structure is preserved on reduction but not on oxidation. ${ }^{125}$ For this grid, a total of ten reduction steps, some ligandbased and some metal-based, can be discerned, while for the analogous grid formed by ligand 21 (Fig. 4), differing only in the lack of the

35 2-phenyl group, as many as twelve fully reversible, one-electron reductions are apparent (Fig. 7). ${ }^{125}$ This is but one example of the influence of ligand substituents upon grid electrochemistry, other systematic studies including those of heterobimetallic species. ${ }^{104}$ The ability to localise an added electron in a ligand orbital raises the possibility of the operation of the Nagaoka mechanism, whereby spin on the ligands interacts under very particular conditions with that on adjacent metal-ion centres to produce an overall spin maximisation, so that certain charge states are associated with exceptionally high magnetisation (indeed, this was realised in the case of the [2x2] Co(II) metallogrids 40 formed with ligand 22 (Fig. 4) at low temperatures). ${ }^{126,127}$

In contrast to the [2x2] $\mathrm{Co}$ (II) grids just discussed, numerous $\mathrm{Mn}$ (II) grids are known to display multiple well-defined, fully reversible, oxidation processes. ${ }^{30,31,33,34} \mathrm{~A}$ further point of contrast is that many of these grids are [3x3] species in which there are non-equivalent corner, edge and central sites of the Mn ions. Thus, there is a particularly clear separation of the potentials associated with the oxidation events at these different sites. The presence of bridging acylhydrazonato- $\mathrm{O}$ atoms within these complexes promotes electronic and magnetic

45 interactions between the Mn centres, one consequence being the especially rich electrochemistry of the [3x3] grids, and another the relatively unusual ease of isolation of a mixed oxidation state species ( $\mathrm{Mn}(\mathrm{III}) 4 \mathrm{Mn}(\mathrm{II}) 5) .{ }^{124}$ An important aspect of the structural characteristics of these grids is that the metal array remains close to planar, a feature which is not necessarily readily maintained as the size of grids increases, ${ }^{30,32,85}$ and a feature which can be critical for efficient orientation of the grids on surfaces (see later). Overall, given that grids formed from redox-inactive metal ions such as $\mathrm{Zn}$ (II) can still display ligand-based electrochemistry modified by the presence of the

50 metal ion, there is a remarkably broad range of electrochemical behaviour, spanning strongly oxidising to strongly reducing situations, available for exploitation in metallogrid systems.

\section{Physical properties of metallogrids - responses to physical stimuli}

An area of intense current research interest is the development of metallosupramolecular complexes capable of acting as single-molecule magnets (SMMs) due to their potential for application in information storage devices. ${ }^{128-131}$ In contrast to conventional bulk magnets, ${ }_{55}$ SMMs do not require collective long range ordering of magnetic moments, and SMM behaviour is typically demonstrated through AC oscillating field magnetic data, and an out of phase frequency dependent response at the single molecule level. ${ }^{129-132}$ Magnetic coupling of paramagnetic metal ions in metallogrids can result in multi-level electronic systems where each level differs in spin and therefore in its 
magnetic properties. ${ }^{30,31,33,34}$ In cases where there is a significant energy barrier for the reversal of the direction of molecular magnetization, and the magnetic susceptibility versus external field loop displays a hysteresis, the materials may be considered as SMMs, although this may depend strongly on both the temperature and the metal ion involved, as illustrated by the recent discovery of tetranuclear lanthanide ion grids showing SMM properties. ${ }^{132}$ Metallogrids are potentially a particularly interesting class of SMM (of course, not all polynuclear 5 species are necessarily so) due to the ease with which it is possible to rationally tune their structures and thereby their magnetic properties. As noted above, the magnetic properties of [2x2] metallogrids formed from ligand $\mathbf{2 3}$ (Fig. 8) with either Fe(II) ions or Co(II) ions can be extremely sensitive to the injection of a single electron at a ligand site, ${ }^{126,133}$ while intramolecular exchange coupling between paramagnetic metal ion centres in grids ${ }^{30,31,33,34}$ can be associated with ferromagnetism, ${ }^{134}$ antiferromagnetism ${ }^{103,135}$ and even metamagnetism, ${ }^{136}$ the last manifesting itself as a notable increase in the magnetisation of a material with a small change in an externally applied magnetic field 10 (see Fig. 9). The Thompson group has made a number of notable contributions to the literature on the subject of metallogrids displaying SMM behaviour, including early works concerning homo- and hetero-metallic grid complexes such as those formed from ligands with the transition metals copper and iron, ${ }^{137,138}$ as well as, very recently, the [2x2] metallogrids formed from ligand 24 (Fig. 8) with Dy(III) ions (see Fig. 10). ${ }^{132}$ Other work ${ }^{30,31,33,34,139}$ has shown that alkoxo-O bridging of $\mathrm{Mn}(\mathrm{II}), \mathrm{Co}(\mathrm{II})$ and Ni(II) ions in grids is usually associated with antiferromagnetic coupling, while ferromagnetic coupling is usual in $\mathrm{Cu}(\mathrm{II})$ systems due to the orthogonality of the partially occupied 15 orbitals. Both theoretical and experimental studies ${ }^{140-142}$ of the [2x2] $\mathrm{Cu}$ (II) grids formed from ligands $\mathbf{2 5}$ and $\mathbf{2 6}$ (both depicted in Fig. 8 ) have also assigned the ferromagnetism of the grid formed from $\mathbf{2 5}$ to the orthogonality of the "magnetic" orbitals but it is important to note that the properties of the grid derived from $\mathbf{2 6}$ were found to be markedly dependent on the counter anion in the solid state, with the perchlorate exhibiting antiferromagnetic coupling while the nitrate shows both ferro- and antiferro-magnetic couplings. The ability to change the counter ion of charged grid species is a subtle way of controlling their properties and obviously adds considerably to the diversity 20 of systems obtainable.

An aspect of the magnetism of transition metal complexes in general that has been widely studied concerns the phenomenon of "spin crossover" (SCO). In certain cases, those of Fe(II), Fe(III) and Co(II) being particularly well-known, ${ }^{143}$ an equilibrium can be observed between states in which the number of unpaired electrons formally located on the metal ion differs. Such behaviour has been well

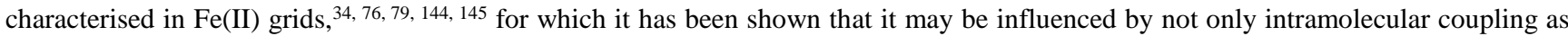
25 just discussed, but also by a variety of physical stimuli (pressure, temperature, light). More detailed consideration of SCO in grid complexes is given later in relation to its possible applications in molecular electronics.

\section{Hierarchical assembly of metallogrid complexes and the emergence of new properties}

Appropriate ligand design imparts the potential not only for metal ion coordination and subsequent grid formation, but for grids with peripheral ligand substituents to become capable of further hierarchical assembly via supramolecular interactions (such as electrostatic, 30 hydrophobic and $\pi-\pi$ interactions, van der Waals forces, hydrogen-bonding and metal coordination) in the solution or solid state. It is therefore possible to design metallogrids capable of self-recognition and self-aggregation, yielding one-, two- or three-dimensional arrays which may be considered as metallosupramolecular polymers. ${ }^{14,60,61,63,65,67}$ For example, hydrogen bonding within the lattices of the Co(II) metallogrids formed from ligands $\mathbf{2 7}$ and $\mathbf{2 8}$ (both depicted in Fig. 11) results in the formation of one-dimensional chains of the metallogrids, ${ }^{146}$ while the use of azole-unit-substituted ligands such as $\mathbf{2 9}$ (Fig. 11) results in complicated two-dimensional sheets of H35 bonds involving the grids and their counter-anions. ${ }^{145}$ The [2x2] $\mathrm{Zn}$ (II) grid formed from ligand $\mathbf{3 0}$ (Fig. 11) was designed to assemble into supramolecular polymers in organic solvents through a combination of supramolecular interactions (i.e. hydrogen bonding interactions between the urea moieties in the ligands, van der Waals interactions between the long alkyl chains in the ligands, and solvent-solute interactions), and in aromatic solvents such as toluene, the supramolecular polymers were observed to form three-dimensional networks of fibrillar assemblies with nanometre-scale diameters and micrometre-scale lengths, the sample-spanning nature of which resulted in gelation 40 of the solvent (see Fig. 12). ${ }^{94}$ This hierarchical assembly process of the [2x2] metallogrid units resulted in the emergence of two new properties: 1) immobilization of the solvent through capillary forces (i.e. gel formation), and 2) observation of a thermoreversible gel transition temperature (i.e. the temperature at which the gel becomes a sol).

Ligand substituents which incorporate donor atoms can enable grid aggregation through metal ion coordination, provided of course that these substituents do not perturb the initial grid formation, and that any added metal ion is preferentially bound to the substituents and not 45 to the grid-forming sites. Thus, in the Fe(II) grids formed by ligands $\mathbf{3 1}$ and $\mathbf{3 2}$ (both depicted in Fig. 11), the pyridyl-N groups of the substituents remain free (in the absence of excess Fe(II)) and can be used, for example, in the case of 31, to coordinate La(III), resulting in the formation of one-dimensional La-bridged chains of grids in the solid state, or in the case of 32, to coordinate Ag(I), resulting in twodimensional, Ag-bridged sheets of grids (see Fig. 13). ${ }^{147}$ The different locations of the N-donor atoms in the pendant pyridyl units appear to be a useful way of controlling the form of solid state aggregation. As described above, self-association of grids based on an oximato50 ligand can occur via deprotonation of the oxime hydroxyl group and its displacement of a unidentate ligand on another grid. ${ }^{123}$

Since the metallogrid assembly process itself involves a change in the coordination environment of the metal ion, in certain cases, notably involving $\mathrm{Fe}(\mathrm{II})$ and $\mathrm{Co}(\mathrm{II})$, it may be associated with significant changes in the properties associated with the metal ion, a particularly important instance, noted above, being that of a spin-state change and the possibility of observing a 'spin crossover'. This phenomenon in grid systems is discussed in detail later, but it may be noted here that from the study of the Fe(II) grids of both $\mathbf{3 1}$ and $\mathbf{3 2}$ 55 there is evidence of hindrance of the spin crossover process with increasing dimensionality of the solid state assemblies. ${ }^{147}$

\section{Self-assembly of thin films of metallogrids for nanoscale electronic/spintronic devices}


The implementation of "top-down" manufacturing processes (such as lithography) during the last fifty years has revolutionized computational technologies and concomitantly our lives. However, the fabrication of small electronic devices via "top-down" processes is more challenging and therefore expensive as the nanometre scale is approached. Consequently, researchers have investigated the application of "bottom-up" approaches (supramolecular chemistry), or a combination of both "top-down" and "bottom-up" approaches for 5 the preparation of nanoscale electronic devices. ${ }^{148-151}$ The physicochemical properties of metallosupramolecular grid complexes have been identified as being particularly promising for nanoscale electronic devices. ${ }^{34}$

Two dimensional arrays of electronically and magnetically active structures are of particular interest for the next generation of nanoscale electronic devices, ${ }^{152}$ and one aspect of relevance to the transfer of metallogrids from laboratory-based studies to high-tech applications is their orientation relative to an underlying substrate to which they may be attached, particularly for applications in which well-organized 10 arrays of addressable metal ions are of interest. That metallogrids are essentially "flat" molecules makes them especially attractive as species that may provide an array of metal ions lying in a plane parallel to the surface to which the grid is attached. ${ }^{124}$ Below the different methods which have been used to prepare arrays of metallogrids are summarized, paying particular attention to the way that the specific method and ligands employed affect the orientation of the metallogrids relative to the underlying substrate.

One method of thin film formation is the self-assembly of metallogrids at the interface of two fluids. Indeed, in seminal work, the [2x2] ${ }_{15} \mathrm{Co}$ (II) grid formed from ligand $\mathbf{3 3}$ (Fig. 14) was found to self-assemble at the air-water interface yielding thin films, and these assemblies could be transferred onto various solid supports (e.g. mica, quartz). ${ }^{153}$ Films formed from the [2x2] metallogrids had average thicknesses of approximately $1.7 \mathrm{~nm}$, consistent with monolayer formation but grazing incidence X-ray diffraction data suggested that the films were not highly crystalline, and that the grids were not oriented in any particular direction. Similarly, [3x3] Ag(I) grids formed from ligands $\mathbf{3 4}$ and 35 (Fig. 14) self-assembled at air-water interfaces and could also be transferred onto various solid supports. Films of the [3x3] 20 metallogrids formed from ligand $\mathbf{3 4}$ had average thicknesses of $2.0 \mathrm{~nm}$ (consistent with bilayer formation), whereas those formed from ligand $\mathbf{3 5}$ had average thicknesses of $1.2 \mathrm{~nm}$ (consistent with a monolayer of the metallogrid). Grazing incidence X-ray diffraction and specular X-ray reflectivity data indicated that both films formed from the [3x3] grids were crystalline and moreover that the plane of the metallogrids formed from ligand $\mathbf{3 4}$ was aligned perpendicular to the air-water interface, whereas for those formed from ligand $\mathbf{3 5}$, this plane was aligned parallel to the air-water interface. ${ }^{153}$ Thin films can also be prepared via self-assembly at oil-water interfaces, as 25 demonstrated with [2x2] $\mathrm{Ag}(\mathrm{I})$ grids formed from ligand 36 (Fig. 14) which self-assembled into crystalline films with average thicknesses of $1.4 \mathrm{~nm}$ (consistent with a monolayer), in which the metallogrids were oriented with their planes aligned perpendicular to the oil-water interface. ${ }^{154}$ Thin films of metallogrids can also be prepared via the Langmuir-Blodgett technique as demonstrated with [2x2] Co(II) grids formed from ligand 37 (Fig. 14). The presence of hydroxyl moieties on this ligand resulted in the formation of a two-dimensional network of hydrogen bonds between the metallogrids in the solid state, and atomic force microscopy revealed rod-like features on the surface of the 30 films which may have been due to the formation of metallosupramolecular polymers mediated by hydrogen bonding interactions between the hydroxyl moieties on the constituent metallogrids. ${ }^{155}$ Hydrogen bonding, both inter- and intra-molecular, is a common feature of numerous crystal structure determinations on grids (for pertinent examples, see ${ }^{86,87,93,99,106,145}$ ), although as an aspect of ligand design its systematic exploitation is relatively recent.

Although adsorption at the fluid-fluid interface is an effective method of thin film formation, dip-coating and drop casting were found 35 to be more effective at producing monolayers of well-organized metallogrids. ${ }^{156,157}$ Indeed, monolayers of [2x2] Co(II) grids formed from ligand 33 produced via drop casting on graphite, yielded films in which the plane of the metallogrids was parallel to the surface of the graphite; whereas, monolayers of [2x2] Co(II) grids formed from ligand 38 (Fig. 14) produced via drop casting, yielded films in which the plane was perpendicular to the surface of the graphite. The differences in the orientation of the metallogrids was ascribed to contributions to molecular packing due to the different positions of the methyl groups on the ligands, probably modulated by interactions with the 40 counterions, $\mathrm{AsF}_{6}-$ and $\mathrm{PF}_{6}-$ for ligands $\mathbf{3 3}$ and $\mathbf{3 8}$ respectively. It is noteworthy that it is possible for such anions to be included within the central cavity of a grid without direct coordination to the metal centres, ${ }^{158}$ just as in solvent inclusion, ${ }^{159,} 160$ grids of course being of interest as a type of solid potentially capable of gas absorption. ${ }^{161}$ It is possible to remove individual metallogrids from such surfaces upon application of a short negative voltage pulse from a scanning tunnelling microscope tip ( $\left.\mathrm{V}_{\text {tip }}=-0.5 \mathrm{~V}, 1 \mathrm{~ms}\right),{ }^{156,157}$ and to extend this to multiple removals over a larger area, a procedure which may be of interest for writing patterns of metallogrids and other species (e.g. 45 conducting polymers) on various substrates. ${ }^{162}$

Films of [2x2] Co(II) grids formed from ligand 32, having 4-pyridyl substituents oriented above and below the plane of the metallogrid, have been produced via drop casting on highly ordered pyrolitic graphite (HOPG). ${ }^{163}$ Scanning tunnelling microscope (STM) images of the films were, however, difficult to obtain due to the fact that the metallogrids interacted rather weakly with the HOPG compared to Co(II) metallogrids formed from either $\mathbf{3 3}$ or $\mathbf{3 8}$ and lacking pyridyl substituents, ${ }^{156,157}$ and this reduced affinity appeared to be a consequence of ${ }_{50}$ interdigitation of these substituents between metallogrids (akin to the inclusion of benzene in the cavity ${ }^{159}$ of $\mathrm{Cu}$ (II) metallogrids formed from ligand 39 (Fig. 14)). In all these cases, orientations of the metallogrid planes both parallel and perpendicular to the HOPG surface were evident. Similarly, for monolayers of [3x3] Mn(II) metallogrids formed from ligands 40-44 (all depicted in Fig. 14) obtained by drop casting, there was no clear preference for the orientation of the plane of the metallogrids relative to the plane of the surface, but current imaging tunnelling spectroscopy (CITS) did allow the visualization of the positions of each of the individual metal ions within metallogrids 55 which were oriented parallel to the underlying substrate (Fig. 15) ${ }^{90,124}$ A subsequent study showed that [4x4] and [5x5] Mn(II) metallogrids formed from ligands $\mathbf{4 5}$ and $\mathbf{4 6}$ (both depicted in Fig. 14) self-organized into well-ordered linear arrays long the monatomic step edges of HOPG, with the plane of the metallogrids parallel to the underlying graphite surface (Fig. 15). ${ }^{30,31,33,34,90}$ This was also seen with [2x2] Co(II) metallogrids formed from ligand $\mathbf{2 3} .^{80}$ 
The stability of monolayers of [2x2] metallogrids adsorbed on HOPG surfaces can be enhanced by appropriate ligand substituents such as long alkyl chains. ${ }^{164,165}$ However, while attractive van der Waals interactions between alkyl chains on the Fe(II) metallogrid formed from ligand 47 (Fig. 14) and the surface markedly improved the stability of deposited monolayers, there was no clear preference for the orientation of the plane of the metallogrids with respect to the plane of the underlying substrate. ${ }^{164}$ In contrast, annealed monolayers of 5 [2x2] Co(II) metallogrids formed from ligand 48 (Fig. 14) were found to have the metallogrid planes oriented perpendicular to the underlying HOPG surface (see Fig. 16). ${ }^{165,166}$

Deposition of monolayers of metallogrids on metallic surfaces (e.g. gold) is of interest for a variety of technological applications (particularly transistors), ${ }^{30,31,33,34}$ and one way in which to achieve this is to design ligands that interact specifically with these substrates. ${ }^{34}$,

76 The ligands 40 and 41, for example, were designed to exploit metal-halide and metal-sulfur interactions and this was elegantly 10 demonstrated in the formation of monolayers of the Mn(II) metallogrids on gold, STM studies revealing the metallogrids to be oriented with their plane parallel to the plane of the underlying gold surface. ${ }^{167,168}$ Although the greater affinity of sulfur than of chlorine for gold resulted in much more stable monolayers for the metallogrid incorporating $\mathbf{4 1}$, the ligand itself, even when bound in the metallogrid, is somewhat unstable and its conversion to thioether derivatives such as $\mathbf{4 2}$ and $\mathbf{4 3}$ was found to be advantageous. ${ }^{124}$

\section{Towards application as nanoscale electronic/spintronic devices}

15 As noted above, two dimensional arrays of electronically and magnetically active structures are of particular interest for the next generation of nanoscale electronic/spintronic devices. ${ }^{143,148-150,169-173}$

Conductance switching in molecular junctions is useful for data storage elements in dynamic random access memory circuits, and the [2x2] Co(II) metallogrids formed from ligand $\mathbf{2 3}$ have potential for such applications (see Fig. 17). ${ }^{174}$ Transport measurements carried out at cryogenic temperatures using a gold break-junction showed that conduction by the metallogrid was dependent upon the vibrational state 20 excited and that random conductance fluctuations occurred, which could be assigned to effects of the motions of the counter anions $\left(\mathrm{BF}_{4}\right.$ ), providing another example of counterion influences upon metallogrid properties. Ab initio quantum chemistry calculations supported the hypothesis of differing electrostatic influences resulting from different positioning of the anions, indicating that a counter ion displacement of ca. $0.5 \AA$ (ca. half the diameter of the counter ion) induces a potential change on the metallogrid complex comparable to that observed experimentally. ${ }^{174}$

25 Devices designed to represent data and perform computation must have distinguishable states and the transition between those states must be conditional, and metallogrids represent interesting nanoscale candidates for such applications. ${ }^{33,}$, 76, 108 As noted earlier, some metallogrids show multiple redox states, up to 11 in the case of the [2x2] Co(II) metallogrid formed from ligand 23, for example, all corresponding to electrochemically reversible processes. ${ }^{125}$ Scanning tunnelling microscopy, scanning tunnelling spectroscopy, current imaging tunnelling spectroscopy (CITS) and density functional theory-based molecular modeling have been used to investigate the 30 electrical properties of thin films of this metallogrid adsorbed on a graphite surface. CITS revealed quadratic arrays of metal ions through which the tunnelling current was markedly increased (see Fig. 18), and no features arising from the presence of the ligands were observed due to the fact that the electronic states of the ligands are located far from the Fermi level and do not therefore play a significant role in the tunnelling current. Furthermore, the first three occupied orbitals were found to be quasi-degenerate in energy with only a few meV separating them, followed by states at -0.55 and $-0.60 \mathrm{eV}$, and a set of states around -0.62 and $0.67 \mathrm{eV}$, while the remaining states were

35 found at around $-1 \mathrm{eV} .{ }^{34,80}$ Similar studies have been made of monolayers on gold of the Mn(II) metallogrid formed from ligand 43. As noted previously, differential pulse voltammograms of this metallogrid in acetonitrile solution show five distinct regions of redox activity (with a large wave at $0.66 \mathrm{~V}$ corresponding to the oxidation of the four $\mathrm{Mn}$ (II) ions located at the corners of the metallogrid complex to $\mathrm{Mn}$ (III), followed by four waves corresponding to the removal of single electrons from the Mn(II) ions located on the sides of the metallogrids) but once the metallogrid was deposited on gold substrates only the first two waves showed up clearly prior to interference 40 due to oxidation of the underlying gold substrate. ${ }^{124}$

Spin crossover (SCO) occurs in metal complexes wherein the spin state of the complex changes due to an external stimulus, and has a variety of applications including display technologies, switches and data storage. ${ }^{143,148-150,169-173}$ The first study ${ }^{144}$ of SCO in a metallogrid system concerned the Fe(II) metallogrid derived from ligand 23, for which it was shown that the spin transition could be triggered by light, pressure and temperature. Mössbauer spectra recorded at various temperatures under permanent irradiation $(\lambda=514 \mathrm{~nm})$ revealed a light-

45 induced thermal hysteresis which is indicative of cooperativity between the metal centres, and this was confirmed via magnetic susceptibility measurements at various temperatures. In theory, any cooperativity/communication between the four metal centres in the metallogrid should manifest itself as multiple steps in the temperature dependence of the magnetic susceptibility data, but the SCO transition was observed to occur gradually (and without hysteresis) possibly due to the presence of poorly ordered counterions and solvent molecules interacting with the metallogrids. ${ }^{144}$ Studies ${ }^{144}$ conducted with a variety of synthetic analogues in order to develop a deeper 50 understanding of structure-function relationships when designing ligands for SCO-active metallogrids, showed that the substituent in the 2-position on the central pyrimidine was of key importance in determining the magnetic properties of the [2x2] Fe(II) metallogrids. Indeed, ligands in which the 2-position substituent is either $\mathrm{H}$ or $\mathrm{OH}$, such as ligands 2 (Fig. 2) and 49 (Fig. 19) provide ligand fields sufficiently strong for the $\mathrm{Fe}(\mathrm{II})$ ions within the metallogrid to remain in their diamagnetic low-spin state over the full temperature range studied. In contrast, substituents that attenuated the ligand field by steric and to a lesser extent electronic effects (such as in ligands $\mathbf{2 3}$ and $\mathbf{3 3}$ ) led to 55 metallogrids that exhibited SCO behaviour (albeit gradual and incomplete) triggered by temperature. ${ }^{144}$ As highlighted previously, the magnetic properties of one and two dimensional hierarchical assemblies of [2x2] Fe(II) metallogrids (formed from ligands 31 or 32) have also been investigated, leading to the conclusion that the spin crossover process is hindered with increasing dimensionality of the 
assemblies. ${ }^{147}$ This was a conclusion drawn from the fact some inhibition of SCO was observed for the one-dimensional assemblies found in the metallogrid derived from ligand $\mathbf{2 5}$, and the inhibition was more marked in the case of two dimensional arrays found for ligand $\mathbf{3 2}$. An explanation of this may be that the transition from low spin to high spin is accompanied by a volume increase about the metal ion, which is inhibited to a greater extent by the more rigid two dimensional arrays than the one dimensional polymer-like assemblies. 5 Ultimately, this makes a very effective case for monolayers of metallogrids being preferred for nanoscale spintronic devices (although the formation of well-defined hierarchical assemblies may prove a useful tool to modulate these properties for specific applications). ${ }^{147}$ Nonetheless, it must be noted that for a family of [2x2] Fe(II) metallogrids where the ligands were designed to be capable of forming at least two-dimensional networks when bound in a metallogrid, ${ }^{145}$ a wide range of temperature-dependent spin crossover behaviour, involving spin changes at 0,1 or $2 \mathrm{Fe}$ (II) centres, is observed for the solid complexes. Concerning cationic metallogrid species, it is likely

10 that the properties are to some extent influenced by the counter-anions and although this was not investigated in this case, a clear illustration that this can indeed be so is provided by the [2x2] Fe(II) metallogrid formed with ligand $\mathbf{5 0}$ (Fig. 19). Here, SCO can be triggered by both light irradiation and temperature change but it is controlled by the nature of the counterions present, and the metallogrid with $\mathrm{PF}_{6}$ counterions was SCO inactive (although displaying antiferromagnetic coupling between the four high spin Fe(II) ions between 8 and 300 $\mathrm{K}$ ), whereas that with $\mathrm{BF}_{4}-$ counterions was $\mathrm{SCO}$ active, displaying a clear two-step transition (involving two of the four Fe(II) centres) in 15 the same temperature range (Fig. 20). ${ }^{175}$ Another instance of a temperature induced change at only one of the four sites of a [2x2] metallogrid is provided by the Fe(II) metallogrid formed with ligand $\mathbf{5 1}$ (Fig. 19), ${ }^{90,176}$ while rather more complicated behaviour is seen for the [2x2] $\mathrm{Fe}$ (II) metallogrid formed by ligand $\mathbf{5 2}$ (Fig. 19), where there is a temperature dependent conversion first of one of the four high-spin centres present at $300 \mathrm{~K}$ to low-spin at $140 \mathrm{~K}$, followed by a partial conversion of a second Fe centre to its low-spin form as the temperature is further reduced (Fig. 21). ${ }^{109}$ Interestingly, this metallogrid can be oxidized to its $\mathrm{Fe}(\mathrm{II})_{2} \mathrm{Fe}(\mathrm{III})_{2}$ form which does not show ${ }_{20} \mathrm{SCO}$ behaviour, yet contains two high-spin Fe(II) and two low-spin Fe(III) centres. There is a contrast here with another mixed-valence $\mathrm{Fe}_{4}$ metallogrid in which all the metal ions are in low spin forms, and the temperature dependence of the magnetic susceptibility can be explained as due to antiferromagnetic coupling between the Fe(III) centres. ${ }^{108}$ Both these mixed-valence systems have been seen as a basis for "quantum cellular automata" 177 due to the energy barrier between the two equivalent states corresponding to alternate diagonal locations of the metals in different oxidation states.

\section{${ }_{25}$ Towards biological applications}

The possible applications of metallogrids are not restricted to those in nanoelectronics. Indeed, through judicious ligand design it is possible to engineer metallogrids with well-defined cavities ${ }^{158-160}$ (or indeed those which are "compact" and thus lacking in an internal cavity), and/or 'multivalent' metallogrids ${ }^{93}$ displaying a specific number of substituents (potentially biologically relevant) with divergent orientations relative to the plane of the metallogrid (see Fig. 22). Nanoscale engineering of this kind is not only useful for the generation 30 of hierarchical assemblies involving metallogrids discussed earlier but also for the creation of metallogrids suited to host-guest chemistry (in which the metallogrid can act as either the guest or host) but research in this direction is only in its nascent stages. In a general context, however, the host-guest chemistry of grid-like molecular rectangles, for example, ${ }^{178,}{ }^{179}$ is quite well developed and the cytotoxic (anticancer) activity of several ruthenium rectangles has recently been demonstrated, ${ }^{50}$ justifying the belief that similar properties may be seen for at least some metallogrids. Indeed, direct evidence for biological activity has been obtained for the [2x2] Ni(II) metallogrid formed

35 by ligand 53 (Fig. 19), which was shown by circular dichroism and absorption spectral studies to intercalate in between the base pairs of calf thymus DNA, causing it to unwind partially. ${ }^{180}$

While it seems reasonable to assume that metallogrids displaying biomolecules such as oligopeptides (as in the $\mathrm{Zn}$ (II) species derived from ligand 54 (Fig. 19) ${ }^{93}$ ) might have a variety of biological applications (e.g. as substrates for bioassays), and it is known from preliminary tests that the water-soluble [2x2] Zn(II) metallogrid formed from ligand $\mathbf{5 5}$ (Fig. 19) and displaying 8 choline-like side chains interacts 40 strongly with sulfonated calixarenes, indicating that that it might serve as an acetylcholine esterase inhibitor, ${ }^{181}$ there is a likely problem with the dissociation of the grids in dilute, aqueous (biological) media. This may not, however, be completely disadvantageous in that many of the ligands used for metallogrid complex formation are very similar in nature to hydrazone species with important medicinal applications. ${ }^{182-184}$ Thus a dissociable metallogrid species, provided its lifetime is not too short, might be used as a delivery device for a therapeutic ligand. This would depend on how greatly the metallogrid and the ligand differ in solubility and in their affinity for biological

45 receptors. Regarding solubility effects, an example is provided in the extremely water soluble (as its alkali metal ion salts) [2x2] Zn(II) metallogrid obtained by reacting the hemi-hydrazide of terephthalic acid with the very water-insoluble 2-phenylpyrimidine-4,6-dialdehyde in the presence of $\mathrm{Zn}(\mathrm{II}){ }^{185}$

An important recent development in metallogrid chemistry has been that of lanthanide(III) species and although the focus in published work has been on SMM behaviour, there is considerable potential for the use of oligonuclear lanthanide complexes in medicine and 50 biology, ${ }^{186}$ and applications of lanthanide metallogrids in, for example, magnetic resonance imaging and cell mapping might well be anticipated.

\section{Conclusions}

The chemistry of metallogrids must be viewed within the context of that of polynuclear metal ion complexes in general ${ }^{19}$ and its value related to any characteristics unique to the metallogrids. The facility and predictability of metallogrid synthesis are certainly major 55 attributes, as is the capacity to readily vary functionality to induce a wide range of both physical and chemical properties. As is apparent 
from the present review, fundamental metallogrid chemistry continues to develop, and the extension into lanthanide chemistry noted above promises to be a significant development beyond that previously focused largely on transition metals. Whether metallogrid complexes have the stability necessary to find real applications in the domains considered herein is perhaps an issue that needs to be further explored, but one obvious exploitation of the ease of metallogrid functionalization would be that of forming macropolycyclic derivatives of vastly

5 increased thermodynamic stability in solution in particular.

\section{Acknowledgements}

I would like to express my deepest thanks to Jack Harrowfield and Jean-Marie Lehn for their constructive criticism on drafts of the manuscript. I warmly thank the authors who were kind enough to supply me with images for inclusion in the manuscript. I am also grateful for financial support provided by an Entente Cordiale Scholarship and the University of Strasbourg.

\section{${ }_{10}$ Notes and references}

a Institut de Science et d'Ingénierie Supramoléculaires (ISIS), Université de Strasbourg, 8 allée Gaspard Monge, 67000, Strasbourg, France.

${ }^{b}$ Department of Biomedical Engineering, The University of Texas at Austin, 107 West Dean Keeton Street, Austin, Texas, TX78712, United States of America.

${ }^{c} J$. Crayton Pruitt Family Department of Biomedical Engineering

15 Biomedical Sciences Building JG-53, P.O. Box 116131, Gainesville, FL 32611-6131, United States of America.

Fax: +13522739221; Tel:+15124713672; E-mail: johnhardyuk@gmail.com

1. J. T. Davis, Angew. Chem. Int. Ed., 2004, 43, 668-698.

20 2. J. T. Davis and G. P. Spada, Chem. Soc. Rev., 2007, 36, 296-313.

3. K. Naka, ed., Biomineralization I: Crystallization and Self-Organization Processes, SpringerVerlag, Berlin Heidelberg, 2007.

4. W. Lucas, Viral Capsids and Envelopes: Structure and Function, John Wiley \& Sons, New York, 2001.

${ }_{25} 5 . \quad$ M. Banerjee, J. A. Speir, M. H. Kwan, R. Huang, P. P. Aryanpur, B. Bothner and J. E. Johnson, J. Virol., 2010, 84, 4737-4746.

6. A. J. Olson, Y. H. Hu and E. Keinan, PNAS, 2007, 104, 20731-20736.

7. N. Holten-Andersen, T. E. Mates, M. S. Toprak, G. D. Stucky, F. W. Zok and J. H. Waite, Langmuir, 2009, 25, 3323-3326.

${ }_{30} 8 . \quad$ P. N. W. Baxter, in Comprehensive Supramolecular Chemistry, eds. J. L. Atwood, J. E. D. Davies, D. D. Macnicol and F. Vögtle, Pergamon/Elsevier Science Ltd, Oxford, 1996, vol. 9.

9. J. M. Lehn, Supramolecular Chemistry: Concepts and Perspectives, $1^{\text {st }}$ ed., Wiley-VCH, Weinheim, 1995.

10. D. L. Caulder and K. N. Raymond, Acc. Chem. Res., 1999, 32, 975-982.

${ }_{35}$ 11. L. K. Thompson, Coord. Chem. Rev., 2002, 233, 193-206.

12. B. Champin, P. Mobian and J. P. Sauvage, Chem. Soc. Rev., 2007, 36, 358-366.

13. J. R. Nitschke, Acc. Chem. Res., 2007, 40, 103-112.

14. M. M. Smulders, I. A. Riddell, C. Browne and J. R. Nitschke, Chem. Soc. Rev., 2013, 42, 17281754.

40 15. Y. E. Alexeev, B. I. Kharisov, T. C. H. Garcia and A. D. Garnovskii, Coord. Chem. Rev., 2010, 254, 794-831.

16. R. Chakrabarty, P. S. Mukherjee and P. J. Stang, Chem. Rev., 2011, 111, 6810-6918.

17. S. Leininger, B. Olenyuk and P. J. Stang, Chem. Rev., 2000, 100, 853-907.

18. J. A. Thomas, Dalton Trans., 2011, 40, 12005-12016.

${ }_{45}$ 19. N. J. Young and B. P. Hay, Chem. Commun., 2013, 49, 1354-1379.

20. J. Harrowfield, Comptes Rendus Chimie, 2005, 8, 199-210.

21. A. J. Thomson and H. B. Gray, Curr. Opin. Chem. Biol., 1998, 2, 155-158.

22. C. Piguet, G. Bernardinelli and G. Hopfgartner, Chem. Rev., 1997, 97, 2005-2062.

23. M. Albrecht, Chem. Soc. Rev., 1998, 27, 281-287.

${ }_{50}$ 24. M. Albrecht, Chem. Rev., 2001, 101, 3457-3497. 
25. M. Albrecht, Top. Curr. Chem., 2004, 248, 105-139.

26. J. L. Schmitt, A. M. Stadler, N. Kyritsakas and J. M. Lehn, Helv. Chim. Acta, 2003, 86, 15981624.

27. A. M. Stadler, N. Kyritsakas, G. Vaughan and J. M. Lehn, Chem. Eur. J., 2007, 13, 59-68.

5 28. X. D. Zheng and T. B. Lu, CrystEngComm, 2010, 12, 324-336.

29. A. Oleksi, A. G. Blanco, R. Boer, I. Uson, J. Aymami, A. Rodger, M. J. Hannon and M. Coll, Angew. Chem. Int. Ed., 2006, 45, 1227-1231.

30. L. N. Dawe, T. S. M. Abedin and L. K. Thompson, Dalton Trans., 2008, 1661-1675.

31. L. N. Dawe, K. V. Shuvaev and L. K. Thompson, Chem. Soc. Rev., 2009, 38, 2334-2359.

${ }_{10}$ 32. A. M. Stadler, Eur. J. Inorg. Chem., 2009, 4751-4770.

33. M. Ruben, J. Rojo, F. J. Romero-Salguero, L. H. Uppadine and J. M. Lehn, Angew. Chem. Int. Ed., 2004, 43, 3644-3662.

34. M. Ruben, J. M. Lehn and P. Muller, Chem. Soc. Rev., 2006, 35, 1056-1067.

35. F. Loiseau, F. Nastasi, A. M. Stadler, S. Campagna and J. M. Lehn, Angew. Chem. Int. Ed., 2007, 46, 6144-6147.

36. F. Puntoriero, S. Campagna, A. M. Stadler and J. M. Lehn, Coord. Chem. Rev., 2008, 252, 2480-2492.

37. G. Marinescu, G. Marin, A. M. Madalan, A. Vezeanu, C. Tiseanu and M. Andruh, Cryst. Growth Des., 2010, 10, 2096-2103.

${ }_{20}$ 38. G. Batta, F. Sztaricskai, M. O. Makarova, E. G. Gladkikh, V. V. Pogozheva and T. F. Berdnikova, Chem. Commun., 2001, 501-502.

39. D. Li, W. Shi and L. Hou, Inorg. Chem., 2005, 44, 3907-3913.

40. Y. Z. Zhang, D. F. Li, R. Clerac, M. Kalisz, C. Mathoniere and S. M. Holmes, Angew. Chem. Int. Ed., 2010, 49, 3752-3756.

${ }_{25}$ 41. S. M. Holmes, D. F. Li, R. Clerac and C. Mathoniere, Abstr. Pap. Am. Chem. Soc., $2007,234$.

42. A. Mishra, S. Ravikumar, S. H. Hong, H. Kim, V. Vajpayee, H. Lee, B. Ahn, M. Wang, P. J. Stang and K. W. Chi, Organometallics, 2011, 30, 6343-6346.

43. A. Mishra, H. Jung, J. W. Park, H. K. Kim, H. Kim, P. J. Stang and K. W. Chi, Organometallics, 2012, 31, 3519-3526.

${ }_{30} 44$ A. Stephenson and M. D. Ward, Dalton Trans., 2011, 40, 10360-10369.

45. F. Sguerra, V. Bulach and M. W. Hosseini, Dalton Trans., 2012, 41, 14683-14689.

46. J. D. Crowley, I. M. Steele and B. Bosnich, Inorg. Chem., 2005, 44, 2989-2991.

47. F. A. Cotton, L. M. Daniels, C. Lin, C. A. Murillo and S. Y. Yu, J. Chem. Soc. Dalton Trans., 2001, 502-504.

${ }_{35}$ 48. B. Chatterjee, J. C. Noveron, M. J. E. Resendiz, J. Liu, T. Yamamoto, D. Parker, M. Cinke, C. V. Nguyen, A. M. Arif and P. J. Stang, J. Am. Chem. Soc., 2004, 126, 10645-10656.

49. J. C. Noveron, I. Cruz-Campa, N. Lopez, H. Disteldorf, C. V. Nguyen, M. J. E. Resendiz and P. J. Stang, Abstr. Pap. Am. Chem. Soc., 2004, 227, U1289-U1289.

50. V. Vajpayee, Y. H. Song, Y. J. Yang, S. C. Kang, H. Kim, I. S. Kim, M. Wang, P. J. Stang and K. W. Chi, Organometallics, 2011, 30, 3242-3245.

51. Z. Q. Jiang, G. Y. Jiang, F. Wang, Z. Zhao and J. Zhang, Chem. Commun., 2012, 48, 36533655 .

52. M. Fujita, Chem. Soc. Rev., 1998, 27, 417-425.

53. M. Fujita, M. Tominaga, A. Hori and B. Therrien, Acc. Chem. Res., 2005, 38, 369-378.

${ }_{45}$ 54. J. L. Atwood, E. K. Brechin, S. J. Dalgarno, R. Inglis, L. F. Jones, A. Mossine, M. J. Paterson, N. P. Power and S. J. Teat, Chem. Commun., 2010, 46, 3484-3486.

55. S. J. Dalgarno, N. P. Power and J. L. Atwood, Coord. Chem. Rev., 2008, 252, 825-841.

56. Y. K. Kryschenko, S. R. Seidel, D. C. Muddiman, A. I. Nepomuceno and P. J. Stang, J. Am. Chem. Soc., 2003, 125, 9647-9652. 
57. S. R. Seidel and P. J. Stang, Acc. Chem. Res., 2002, 35, 972-983.

58. A. Granzhan, C. Schouwey, T. Riis-Johannessen, R. Scopelliti and K. Severin, J. Am. Chem. Soc., 2011, 133, 7106-7115.

59. D. Fujita, K. Suzuki, S. Sato, M. Yagi-Utsumi, Y. Yamaguchi, N. Mizuno, T. Kumasaka, M. Takata, M. Noda, S. Uchiyama, K. Kato and M. Fujita, Nat. Commun., 2012, 3.

60. J. M. Lehn, Prog. Polym. Sci., 2005, 30, 814-831.

61. J. M. Lehn, Aust. J. Chem., 2010, 63, 611-623.

62. S. Hornig, I. Manners, G. R. Newkome and U. S. Schubert, Macromol. Rap. Commun., 2010, 31, 771-771.

${ }_{10}$ 63. G. R. Whittell, M. D. Hager, U. S. Schubert and I. Manners, Nat. Mater., 2011, 10, 176-188.

64. T. F. De Greef, M. M. Smulders, M. Wolffs, A. P. Schenning, R. P. Sijbesma and E. W. Meijer, Chem. Rev., 2009, 109, 5687-5754.

65. J. D. Fox and S. J. Rowan, Macromol., 2009, 42, 6823-6835.

66. S. J. Rowan, A. Kumar, S. Sivakova, J. D. Fox and R. Marchant, Abstr. Pap. Am. Chem. Soc., 2007, 234.

67. M. O. M. Piepenbrock, G. O. Lloyd, N. Clarke and J. W. Steed, Chem. Rev., 2010, 110, 19602004.

68. L. Chabanne, I. Matas, S. K. Patra and I. Manners, Polym. Chem., 2011, 2, 2651-2660.

69. J. D. Crowley, I. M. Steele and B. Bosnich, Eur. J. Inorg. Chem., 2005, 3907-3917.

${ }_{20}$ 70. O. I. Shchegolikhina, Y. A. Pozdniakova, S. V. Lindeman, A. A. Zhdanov, R. Psaro, R. Ugo, G. Gavioli, R. Battistuzzi, M. Borsari, T. Ruffer, C. Zucchi and G. Palyi, J. Organomet. Chem., 1996, 514, 29-35.

71. G. Mislin, E. Graf, M. Hosseini, A. Bilyk, A. Hall, J. Harrowfield, B. Skelton and A. White, Chem. Commun., 1999, 373-374.

${ }_{25}$ 72. A. Bilyk, J. W. Dunlop, R. O. Fuller, A. K. Hall, J. M. Harrowfield, M. W. Hosseini, G. A. Koutsantonis, I. W. Murray, B. W. Skelton, A. N. Sobolev, R. L. Stamps and A. H. White, Eur. J. Inorg. Chem., 2010, 2127-2152.

73. I. J. Clark, A. Crispini, P. S. Donnelly, L. M. Engelhardt, J. M. Harrowfield, S. H. Jeong, Y. Kim, G. A. Koutsantonis, Y. H. Lee, N. A. Lengkeek, M. Mocerino, G. L. Nealon, M. I. Ogden, Y. C. Park, C. Pettinari, L. Polanzan, E. Rukmini, A. M. Sargeson, B. W. Skelton, A. N. Sobolev, P. Thuery and A. H. White, Aust. J. Chem., 2009, 62, 1246-1260.

74. J. McMurtrie and I. Dance, CrystEngComm, 2005, 7, 216-229.

75. M. T. Youinou, N. Rahmouni, J. Fischer and J. A. Osborn, Angew. Chem. Int. Ed. Engl., 1992, 31, 733-735.

${ }_{35}$ 76. K. Petukhov, M. S. Alam, H. Rupp, S. Strömsdörfer, P. Müller, A. Scheurer, R. W. Saalfrank, J. Kortus, A. Postnikov, M. Ruben, L. K. Thompson and J. M. Lehn, Coord. Chem. Rev., 2009, 253, 2387-2398.

77. $\quad$ L. N. Dawe and L. K. Thompson, Dalton Trans., 2008, 3610-3618.

78. U. S. Schubert, A. Winter, G.R. Newkome, Terpyridine-based Materials: For Catalytic, Optoelectronic and Life Science Applications, Wiley-VCH, Weinheim, 2011.

79. $\quad$ K. S. Murray, Aust. J. Chem., 2009, 62, 1081-1101.

80. M. S. Alam, S. Stromsdorfer, V. Dremov, P. Muller, J. Kortus, M. Ruben and J. M. Lehn, Angew. Chem. Int. Ed., 2005, 44, 7896-7900.

81. O. Waldmann, J. Hassmann, P. Muller, G. S. Hanan, D. Volkmer, U. S. Schubert and J. M. ${ }_{45} \quad$ Lehn, Phys. Rev. Lett., 1997, 78, 3390-3393.

82. T. Bark, M. Duggeli, H. Stoeckli-Evans and A. von Zelewsky, Angew. Chem. Int. Ed., 2001, 40, 2848-2851.

83. P. N. Baxter, J. M. Lehn, G. Baum and D. Fenske, Chem. Eur. J., 2000, 6, 4510-4517.

84. M. Barboiu, E. Petit, A. van der Lee and G. Vaughan, Inorg. Chem., 2006, 45, 484-486. 
85. M. Barboiu, G. Vaughan, R. Graff and J. M. Lehn, J. Am. Chem. Soc., 2003, 125, 1025710265.

86. Y. S. Moroz, K. Kulon, M. Haukka, E. Gumienna-Kontecka, H. Kozlowski, F. Meyer and I. O Fritsky, Inorg. Chem., 2008, 47, 5656-5665.

5 87. Y. S. Moroz, L. Szyrwiel, S. Demeshko, H. Kozlowski, F. Meyer and I. O. Fritsky, Inorg. Chem., 2010, 49, 4750-4752.

88. S. Toyota, C. R. Woods, M. Benaglia, R. Haldimann, K. Wärnmark, K. Hardcastle and J. S. Siegel, Angew. Chem. Int. Ed. Engl, 2001, 40, 751-754.

89. A. M. Stadler and J. Harrowfield, Inorg. Chim. Acta, 2009, 362, 4298-4314.

10 90. S. K. Dey, T. S. M. Abedin, L. N. Dawe, S. S. Tandon, J. L. Collins, L. K. Thompson, A. V. Postnikov, M. S. Alam and P. Muller, Inorg. Chem., 2007, 46, 7767-7781.

91. A. M. Stadler, C. Burg, J. Ramirez and J. M. Lehn, Chem. Commun., 2013, 49, 5733-5735.

92. Y. Yu, D. S. Kalinowski, Z. Kovacevic, A. R. Siafakas, P. J. Jansson, C. Stefani, D. B. Lovejoy, P. C. Sharpe, P. V. Bernhardt and D. R. Richardson, J. Med. Chem., 2009, 52, 52715294.

93. X. Y. Cao, J. Harrowfield, J. Nitschke, J. Ramirez, A. M. Stadler, N. Kyritsakas-Gruber, A. Madalan, K. Rissanen, L. Russo, G. Vaughan and J. M. Lehn, Eur. J. Inorg. Chem., 2007, 2944-2965.

94. J. G. Hardy, X. Y. Cao, J. Harrowfield and J. M. Lehn, New J. Chem., 2012, 36, 668-673.

20 95. L. Ma, B. O. Patrick and D. Dolphin, Chem. Commun., 2011, 47, 704-706.

96. W. A. Gobeze, V. A. Milway, B. Moubaraki, K. S. Murray and S. Brooker, Dalton Trans., 2012, 41, 9708-9721.

97. S. O. Malinkin, Y. S. Moroz, L. V. Penkova, M. Haukka, A. Szebesczyk, E. GumiennaKontecka, V. A. Pavlenko, E. Nordlander, F. Meyer and I. O. Fritsky, Inorg. Chim. Acta, 2012, 392, 322-330.

25

98. J. R. Nitschke and J. M. Lehn, PNAS, 2003, 100, 11970-11974.

99. A. R. Stefankiewicz, J. Harrowfield, A. Madalan, K. Rissanen, A. N. Sobolev and J. M. Lehn, Dalton Trans., 2011, 40, 12320-12332.

100. N. Parizel, J. Ramirez, C. Burg, S. Choua, M. Bernard, S. Gambarelli, V. Maurel, L. Brelot, J. M. Lehn, P. Turek and A. M. Stadler, Chem. Commun., 2011, 47, 10951-10953.

101. A. Meme, A. R. Stefankiewicz, J. Harrowfield, X. Y. Cao, J. Huuskonen, K. Rissanen, J. M. Lehn, H. Nierengarten and E. Leize, Eur. J. Inorg. Chem., 2012, 647-654.

102. H. Nierengarten, E. Leize, E. Breuning, A. Garcia, F. Romero-Salguero, J. Rojo, J. M. Lehn and A. Van Dorsselaer, J. Mass Spectrom., 2002, 37, 56-62.

${ }_{35}$ 103. D. M. Bassani, J. M. Lehn, K. Fromm and D. Fenske, Angew. Chem. Int. Ed., 1998, 37, 23642367.

104. D. M. Bassani, J. M. Lehn, S. Serroni, F. Puntoriero and S. Campagna, Chem. Eur. J., 2003, 9, 5936-5946.

105. L. H. Uppadine and J. M. Lehn, Angew. Chem. Int. Ed., 2004, 43, 240-243.

${ }_{40}$ 106. J. Hausmann and S. Brooker, Chem. Commun., 2004, 1530-1531.

107. A. Petitjean, N. Kyritsakas and J. M. Lehn, Chem. Commun., 2004, 1168-1169.

108. Y. G. Zhao, D. Guo, Y. Liu, C. He and C. Y. Duan, Chem. Commun., 2008, 5725-5727.

109. B. Schneider, S. Demeshko, S. Dechert and F. Meyer, Angew. Chem. Int. Ed., 2010, 49, 92749277.

${ }_{45}$ 110. F. A. L. Anet, S. S. Miura, J. Siegel and K. Mislow, J. Am. Chem. Soc., 1983, 105, 1419-1426.

111. R. Hoogenboom, D. Wouters and U. S. Schubert, Macromol., 2003, 36, 4743-4749.

112. R. Hoogenboom, B. C. Moore and U. S. Schubert, Chem. Commun., 2006, 4010-4012.

113. R. Hoogenboom, B. C. Moore and U. S. Schubert, Macromol. Rap. Commun., 2010, 31, 840845. 
114. J. R. Price, N. G. White, A. Perez-Velasco, G. B. Jameson, C. A. Hunter and S. Brooker, Inorg. Chem., 2008, 47, 10729-10738.

115. J. F. Mano, Adv. Eng. Mater., 2008, 10, 515-527.

116. M. A. C. Stuart, W. T. S. Huck, J. Genzer, M. Müller, C. Ober, M. Stamm, G. B. Sukhorukov, I. Szleifer, V. V. Tsukruk, M. Urban, F. Winnik, S. Zauscher, I. Luzinov and S. Minko, Nat. Mater., 2010, 9, 101-113.

117. M. Ruben, J. M. Lehn and G. Vaughan, Chem. Commun., 2003, 1338-1339.

118. L. H. Uppadine, J. P. Gisselbrecht and J. M. Lehn, Chem. Commun., 2004, 718-719.

119. P. N. Baxter, R. G. Khoury, J. M. Lehn, G. Baum and D. Fenske, Chem. Eur. J., 2000, 6, 41404148.

120. J. Ramirez, A. M. Stadler, N. Kyritsakas and J. M. Lehn, Chem. Commun., 2007, 237-239.

121. A. M. Stadler, N. Kyritsakas, R. Graff and J. M. Lehn, Chem. Eur. J., 2006, 12, 4503-4522.

122. T. S. M. Abedin, L. K. Thompson and D. O. Miller, Chem. Commun., 2005, 5512-5514.

123. Y. S. Moroz, S. Demeshko, M. Haukka, A. Mokhir, U. Mitra, M. Stocker, P. Muller, F. Meyer and I. O. Fritsky, Inorg. Chem., 2012, 51, 7445-7447.

124. V. A. Milway, T. S. M. Abedin, V. Niel, T. Kelly, L. N. Dawe, S. K. Dey, D. W. Thompson, D. W. Miller, M. S. Alam, P. Muller and L. K. Thompson, Dalton Trans., 2006, 2835-2851.

125. M. Ruben, E. Breuning, M. Barboiu, J. P. Gisselbrecht and J. M. Lehn, Chem. Eur. J., 2003, 9, 291-299.

${ }_{20}$ 126. C. Romeike, M. R. Wegewijs, M. Ruben, W. Wenzel and H. Schoeller, Phys. Rev. B, $2007,75$.

127. Y. Nagaoka, Phys. Rev., 1966, 147, 392-405.

128. E. Pardo, R. Ruiz-García, J. Cano, X. Ottenwaelder, R. Lescouëzec, Y. Journaux, F. Lloret and M. Julve, Dalton Trans., 2008, 2780-2805.

129. L. Bogani and W. Wernsdorfer, Nat. Mater., 2008, 7, 179-186.

25 130. J. R. Friedman and M. P. Sarachik, Annu. Rev. Condens. Matter Phys., Vol 1, 2010, 1, 109-128.

131. T. Glaser, Chem. Commun., 2011, 47, 116-130.

132. M. U. Anwar, L. K. Thompson, L. N. Dawe, F. Habib and M. Murugesu, Chem. Commun., 2012, 48, 4576-4578.

133. C. Romeike, M. R. Wegewijs, W. Wenzel, M. Ruben and H. Schoeller, Int. J. Quantum Chem., 2006, 106, 994-1000.

134. Z. Q. Xu, L. K. Thompson and D. O. Miller, J. Chem. Soc. Dalton Trans., 2002, 2462-2466.

135. C. J. Matthews, K. Avery, Z. Q. Xu, L. K. Thompson, L. Zhao, D. O. Miller, K. Biradha, K. Poirier, M. J. Zaworotko, C. Wilson, A. E. Goeta and J. A. K. Howard, Inorg. Chem., 1999, 38, 5266-5276.

${ }_{35}$ 136. O. Waldmann, M. Ruben, U. Ziener, P. Muller and J. M. Lehn, Inorg. Chem., 2006, 45, 65356540.

137. V. A. Milway, V. Niel, T. S. M. Abedin, Z. Q. Xu, L. K. Thompson, H. Grove, D. O. Miller and S. R. Parsons, Inorg. Chem., 2004, 43, 1874-1884.

138. Z. Xu, L. K. Thompson, C. J. Matthews, D. O. Miller, A. E. Goeta and J. A. K. Howard, Inorg. Chem., 2001, 40, 2446-2449.

139. T. N. Mandal, S. Roy, S. Konar, A. Jana, S. Ray, K. Das, R. Saha, M. S. El Fallah, R. J. Butcher, S. Chatterjee and S. K. Kar, Dalton Trans., 2011, 40, 11866-11875.

140. S. Roy, T. N. Mandal, A. K. Barik, S. Gupta, R. J. Butcher, M. S. El Fallah, J. Tercero and S. K. Kar, Polyhedron, 2008, 27, 105-112.

${ }_{45}$ 141. S. Roy, T. N. Mandal, A. K. Barik, S. Gupta, M. S. El Fallah, J. Tercero, R. J. Butcher and S. K. Kar, Dalton Trans., 2009, 8215-8226.

142. S. Roy, T. N. Mandal, A. K. Barik, S. Pal, R. Butcher, M. S. El Fallah, J. Tercero and S. K. Kar, Dalton Trans., 2007, 1229-1234.

143. J. F. Letard, P. Guionneau and L. Goux-Capes, Top. Curr. Chem., 2004, 235, 221-249. 
144. E. Breuning, M. Ruben, J. M. Lehn, F. Renz, Y. Garcia, V. Ksenofontov, P. Gutlich, E. Wegelius and K. Rissanen, Angew. Chem. Int. Ed., 2000, 39, 2504-7.

145. A. R. Stefankiewicz, G. Rogez, J. Harrowfield, A. N. Sobolev, A. Madalan, J. Huuskonen, K. Rissanen and J. M. Lehn, Dalton Trans., 2012, 41, 13848-13855.

s 146. E. Breuning, U. Ziener, J. M. Lehn, E. Wegelius and K. Rissanen, Eur. J. Inorg. Chem., 2001, 1515-1521.

147. M. Ruben, U. Ziener, J. M. Lehn, V. Ksenofontov, P. Gutlich and G. B. M. Vaughan, Chem. Eur. J., 2005, 11, 94-100.

148. W. B. Lin, W. J. Rieter and K. M. L. Taylor, Angew. Chem. Int. Ed., 2009, 48, 650-658.

10 149. K. L. Wang, I. Ovchinnikov, F. X. Xiu, A. Khitun and M. Bao, J. Nanosci. Nanotechnol., 2011, 11, 306-313.

150. K. L. Wang and I. Ovchinnikov, Mat. Sci. Forum, 2009, 608, 133-158.

151. T. W. Odom and M. P. Pileni, Acc. Chem. Res., 2008, 41, 1565-1565.

152. F. Pulizzi, Nat. Mater., 2012, 11, 367-367.

${ }_{15} 153$. I. Weissbuch, P. N. W. Baxter, S. Cohen, H. Cohen, K. Kjaer, P. Howes, J. Als-Nielsen, G. Hanan, U. S. Schubert, J. M. Lehn, L. Leiserowitz and M. Lahav, J. Am. Chem. Soc., 1998, 120, 4850-4860.

154. I. Weissbuch, P. Baxter, I. KuzmenkoN. W., H. Cohen, S. Cohen, K. Kjaer, P. B. Howes, J. Als-Nielsen, J. M. Lehn, L. Leiserowitz and M. Lahav, Chem. Eur. J., 2000, 6, 725-734.

${ }_{20} 155$. U. S. Schubert, J. M. Lehn, J. Hassmann, C. Y. Hahn, N. Hallschmid and P. Mueller, ACS Symp. Ser., Funct. Polym., 1998, 704, 248-260.

156. A. Semenov, J. P. Spatz, J. M. Lehn, C. H. Weidl, U. S. Schubert and M. Moller, Appl. Surf. Sci., 1999, 144-45, 456-460.

157. A. Semenov, J. P. Spatz, M. Moller, J. M. Lehn, B. Sell, D. Schubert, C. H. Weidl and U. S. Schubert, Angew. Chem. Int. Ed., 1999, 38, 2547-2550.

158. B. R. Manzano, F. A. Jalaton, I. M. Ortiz, M. L. Soriano, F. G. De la Torre, J. Elguero, M. A. Maestro, K. Mereiter and T. D. W. Claridge, Inorg. Chem., 2008, 47, 413-428.

159. P. N. W. Baxter, J. M. Lehn, B. O. Kneisel and D. Fenske, Chem. Commun., 1997, 2231-2232.

160. J. Ramirez and A. M. Stadler, Z. Anorg. Allg. Chem. 2009, 635, 1348-1351.

${ }_{30}$ 161. H. Kajiro, A. Kondo, K. Kaneko and H. Kanoh, Int. J. Mol. Sci., 2010, 11, 3803-3845.

162. Y. Okawa, M. Akai-Kasaya, Y. Kuwahara, S. K. Mandal and M. Aono, Nanoscale, 2012, 4, 3013-3028.

163. U. Ziener, J. M. Lehn, A. Mourran and M. Moller, Chem. Eur. J., 2002, 8, 951-957.

164. A. Mourran, U. Ziener, M. Moller, E. Breuning, M. Ohkita and J. M. Lehn, Eur. J. Inorg. Chem., 2005, 2641-2647.

165. A. R. Stefankiewicz, G. Rogez, J. Harrowfield, M. Drillon and J. M. Lehn, Dalton Trans., 2009, 5787-5802.

166. G. Pace, A. Stefankiewicz, J. Harrowfield, J. M. Lehn and P. Sarnori, ChemPhysChem, 2009, 10, 699-705.

${ }_{40}$ 167. J. G. Shapter, L. Weeks, L. K. Thompson, K. J. Pope and M. Johnston, Proc. SPIE, 2004, 5275, 59-67.

168. L. Zhao, Z. Xu, H. Grove, V. A. Milway, L. N. Dawe, T. S. Abedin, L. K. Thompson, T. L. Kelly, R. G. Harvey, D. O. Miller, L. Weeks, J. G. Shapter and K. J. Pope, Inorg. Chem., 2004, 43, 3812-3824.

${ }_{45}$ 169. S. A. Wolf, D. D. Awschalom, R. A. Buhrman, J. M. Daughton, S. von Molnar, M. L. Roukes, A. Y. Chtchelkanova and D. M. Treger, Science, 2001, 294, 1488-1495.

170. W. Wernsdorfer, Int. J. Nanotechnol., 2010, 7, 497-522.

171. M. Urdampilleta, S. Klyatskaya, J. P. Cleuziou, M. Ruben and W. Wernsdorfer, Nat. Mater., 2011, 10, 502-506. 
172. M. Urdampilleta, N. Nguyen, J. P. Cleuziou, S. Klyatskaya, M. Ruben and W. Wernsdorfer, Int. J. Mol. Sci., 2011, 12, 6656-6667.

173. R. Vincent, S. Klyatskaya, M. Ruben, W. Wernsdorfer and F. Balestro, Nature, 2012, 488, $357-$ 360.

s 174. E. A. Osorio, M. Ruben, J. S. Seldenthuis, J. M. Lehn and H. S. van der Zant, Small, 2010, 6, 174-178.

175. D. Y. Wu, O. Sato, Y. Einaga and C. Y. Duan, Angew. Chem. Int. Ed., 2009, 48, 1475-1478.

176. K. V. Shuvaev, L. N. Dawe and L. K. Thompson, Dalton Trans., 2010, 39, 4768-4776.

177. J. Y. Jiao, G. J. Long, F. Grandjean, A. M. Beatty and T. P. Fehlner, J. Am. Chem. Soc., 2003, 125, 7522-7523.

178. F. Linares, E. Q. Procopio, M. A. Galindo, M. A. Romero, J. A. R. Navarro and E. Barea, CrystEngComm, 2010, 12, 2343-2346.

179. N. P. E. Barry, J. Furrer, J. Freudenreich, G. Suss-Fink and B. Therrien, Eur. J. Inorg. Chem., 2010, 725-728.

${ }_{15}$ 180. L. Jia, J. Xu, X. M. Xu, L. H. Chen, P. Jiang, F. X. Cheng, G. N. Lu, Q. Wang, J. C. Wu and N. Tang, Chem. Pharm. Bull., 2010, 58, 1077-1080.

181. X. Y. Cao, Ph.D. Thesis, University of Strasbourg, 2009.

182. P. V. Bernhardt, Dalton Trans., 2007, 3214-3220.

183. D. R. Richardson, D. S. Kalinowski, V. Richardson, P. C. Sharpe, D. B. Lovejoy, M. Islam and P. V. Bernhardt, J. Med. Chem., 2009, 52, 1459-1470.

184. P. V. Bernhardt, P. C. Sharpe, M. Islam, D. B. Lovejoy, D. S. Kalinowski and D. R. Richardson, J. Med. Chem., 2009, 52, 407-415.

185. J. Harrowfield and J. M. Lehn, Unpublished.

186. S. A. Cotton and J. Harrowfield, in The Rare Earth Elements: Fundamentals and Applications, ed. D. A. Atwood, Wiley \& Sons, Chichester, 1st ed., 2012, pp. 65-71.

187. A. Thompson and D. Dolphin, Org. Lett., 2000, 2, 1315-1318. 


\section{Figure Legends}
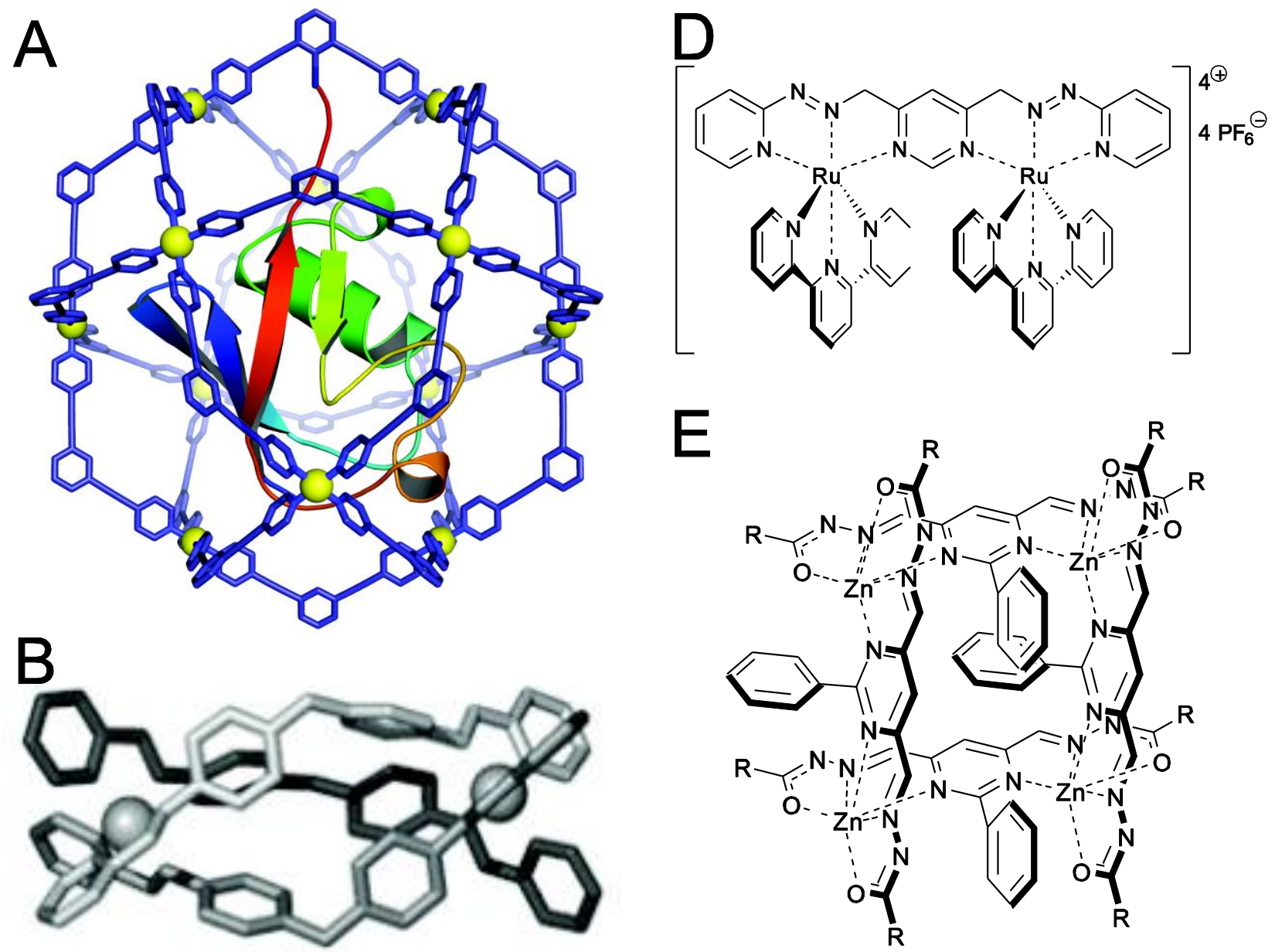

C
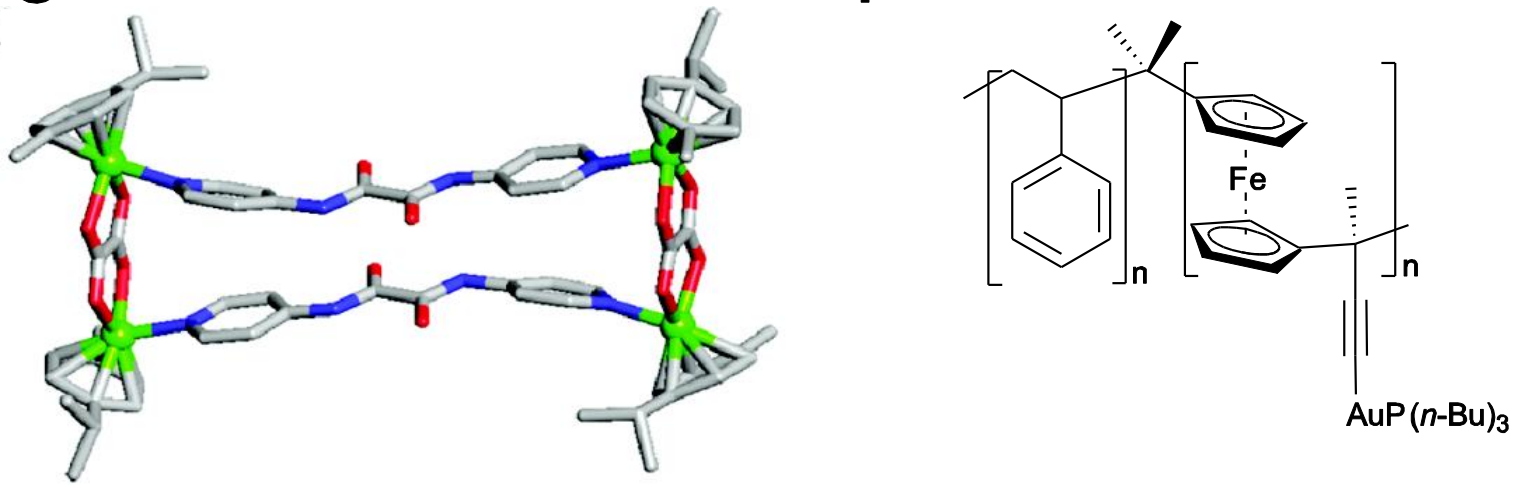

${ }_{5}$ Figure 1. Examples of metallosupramolecular entities. A) Schematic depicting a metallocage encapsulating Ubiquitin, in which the $\mathrm{Pb}(\mathrm{II})$ ions are represented as yellow spheres; ${ }^{59} \mathrm{~B}$ ) a metallosupramolecular helicate, in which the $\mathrm{Fe}(\mathrm{II})$ ions are represented as grey spheres; ${ }^{29} \mathrm{C}$ ) a metallosupramolecular rectangle, in which the $\mathrm{Ru}(\mathrm{II})$ ions are represented as green sphere; $\left.{ }^{50} \mathrm{D}\right) \mathrm{a}$ metallosupramolecular rack; ${ }^{36} \mathrm{E}$ ) a metallosupramolecular grid; ${ }^{94} \mathrm{~F}$ ) a metallosupramolecular ${ }_{10}$ polymer. ${ }^{68} \mathrm{~A}-\mathrm{C}$ are reproduced with the permission of the respective publishers. 
<smiles>c1ccc(-c2ccc(-c3ccccn3)nn2)nc1</smiles>

1<smiles>Cc1nc(N(C)/N=C/c2cccc(CO)n2)cc(N(C)/N=C/c2cccc(CO)n2)n1</smiles><smiles>[R]C(=O)N/N=C/c1cc(/C=N/NC([R])=O)nc(-c2ccccc2)n1</smiles>

7<smiles>CC(=N\O)/C(C)=N/NC(=O)c1cccc(C(=O)N/N=C(C)/C(C)=N/O)n1</smiles>

10<smiles>c1ccc(-c2cc(-c3cccc(-c4ccccn4)n3)ncn2)nc1</smiles>

2<smiles>S=C(NN=C(c1ccccn1)c1ccccn1)NN=C(c1ccccn1)c1ccccn1</smiles>

5<smiles>CN(/N=C/c1ccccn1)c1cc(N(C)/N=C/c2ccccn2)ncn1</smiles>

8<smiles>N/C(=N\N=C(/O)c1cccc(/C(O)=N/N=C(\N)c2ccccn2)n1)c1ccccn1</smiles><smiles>C(=N/Nc1ccccn1)\c1cc(/C=N/Nc2ccccn2)ncn1</smiles><smiles>CN(/N=C/c1ccccn1)c1nc(-c2ccccc2)nc(N(C)/N=C/c2ccccn2)n1</smiles>

9

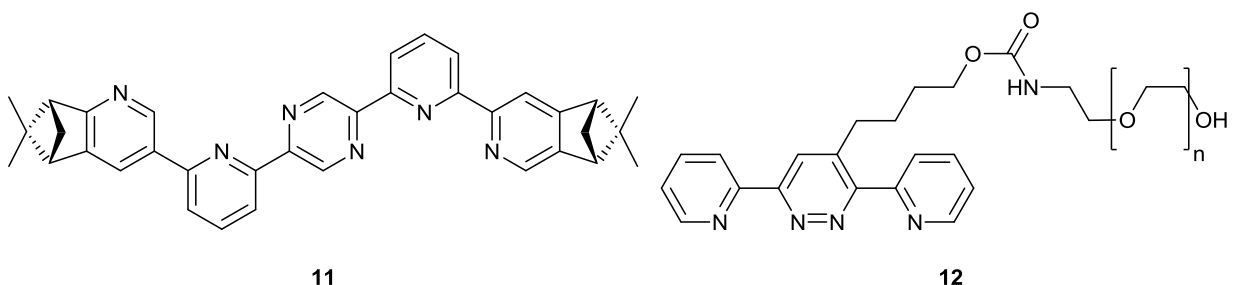

Figure 2. Ligands 1-12 employed in the preparation of metallogrids. 


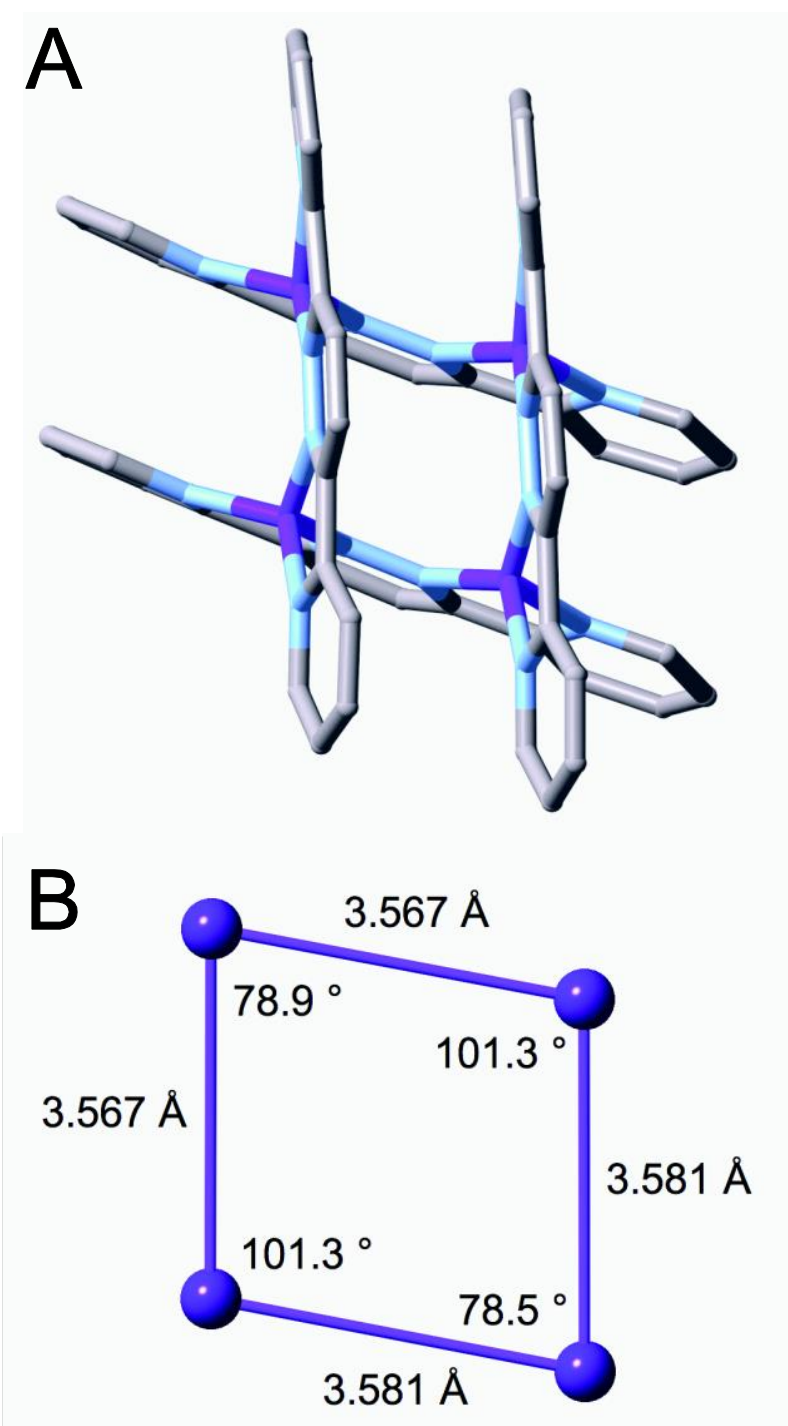

Figure 3. A) A perspective view (stick representation) of the cationic grid unit present in the crystal lattice of $\left.\left[\mathrm{Cu}_{4}(\mathbf{1})_{4}\right]\left(\mathrm{CF}_{3} \mathrm{SO}_{3}\right)_{4} .2 \mathrm{CH}_{3} \mathrm{OH} ; \mathrm{B}\right)$ the dimensions of the $\mathrm{Cu}_{4}$ core. $^{75}$ 
<smiles></smiles><smiles>C/C(=N\O)C(=O)N/N=C(\C)c1ccccn1</smiles><smiles>CCCSc1cc(-c2ccccn2)nc(-c2cc(-c3cc(-c4cc(SCCC)cc(-c5cc(SCCC)cc(-c6cc(-c7cc(SCCC)cc(-c8ccccn8)n7)ncn6)n5)n4)ncn3)ncn2)c1</smiles><smiles>CC(=O)c1cc(-c2ccccn2)nc(-c2cc(-c3cc(C(C)=O)cc(-c4ccccn4)n3)nc(-c3ccccc3)n2)c1</smiles>

16<smiles>CN(/N=C/c1ccccn1)c1cc(N(C)/N=C/c2cc(/C=N/N(C)c3ncnc(N(C)/N=C/c4ccccn4)n3)ncn2)ncn1</smiles>

17

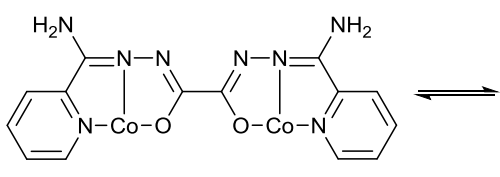

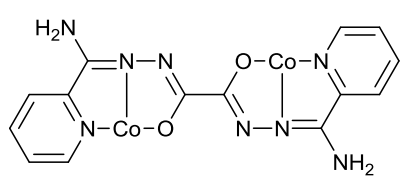

18 cis

18 trans<smiles>CC(=O)c1cc(-c2ccccn2)nc(-c2cc(-c3ccccn3)ncn2)c1</smiles>

Figure 4. Ligands 13-22 employed in the preparation of metallogrids.
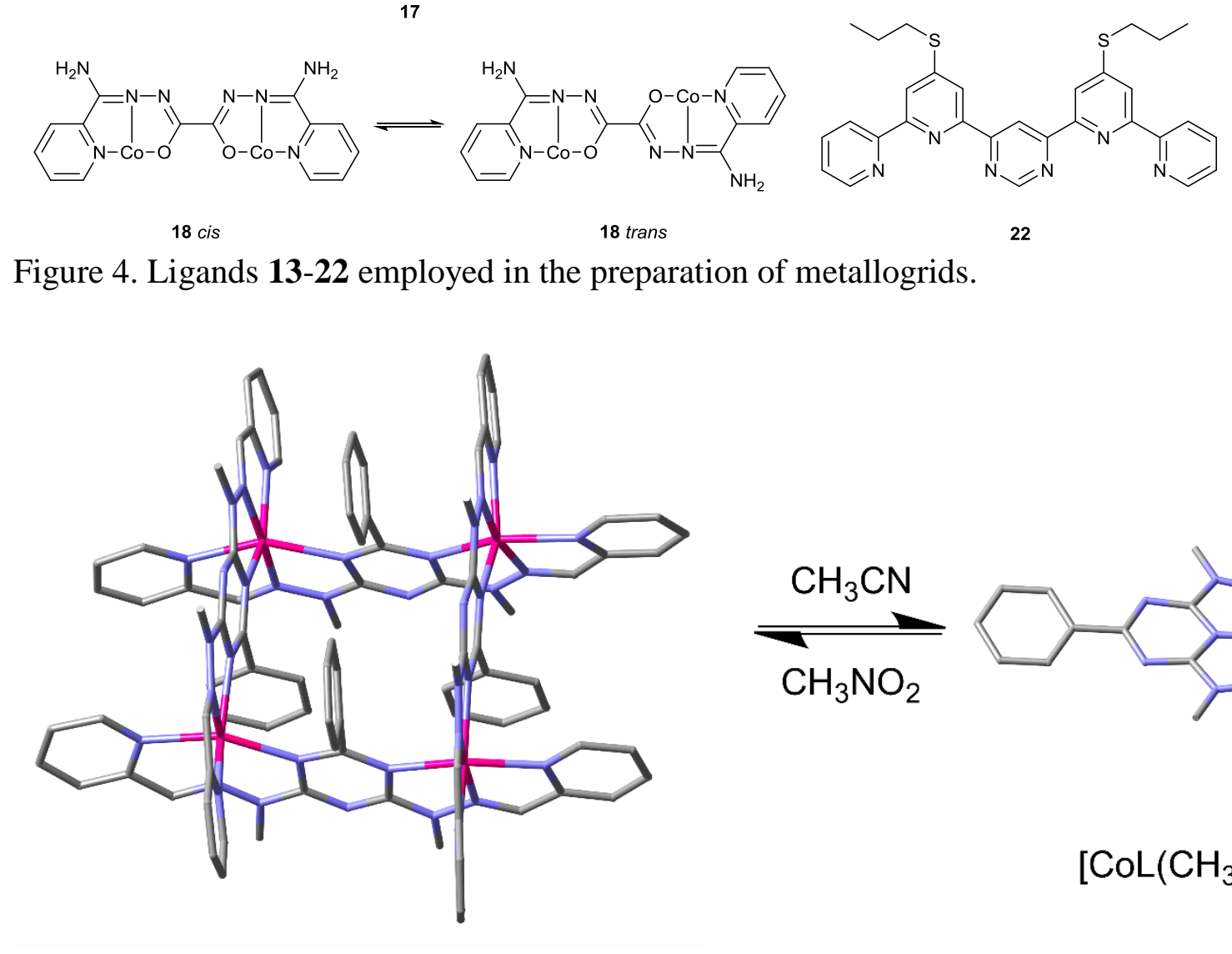

19

21

22

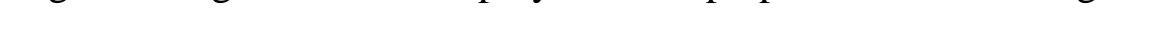

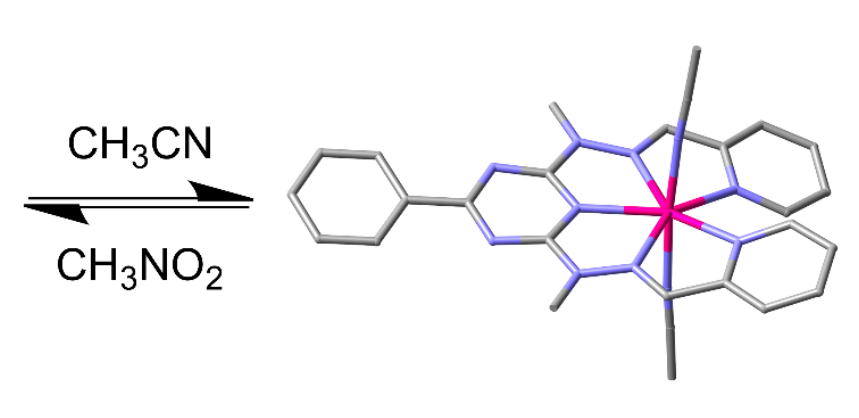

$\left[\mathrm{Co}_{4} \mathrm{~L}_{4}\right]^{8+}$

${ }_{5}$ Figure 5. Solvent triggered reversible conversion of a metallogrid (based on ligand 9) into a pincer-like complex (adapted from the literature ${ }^{120}$ ). 


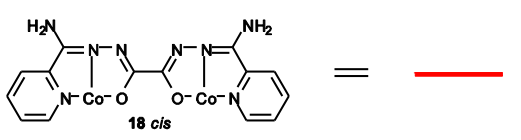

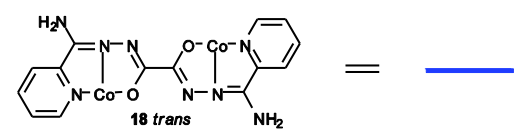<smiles>CPC1CCC1</smiles>
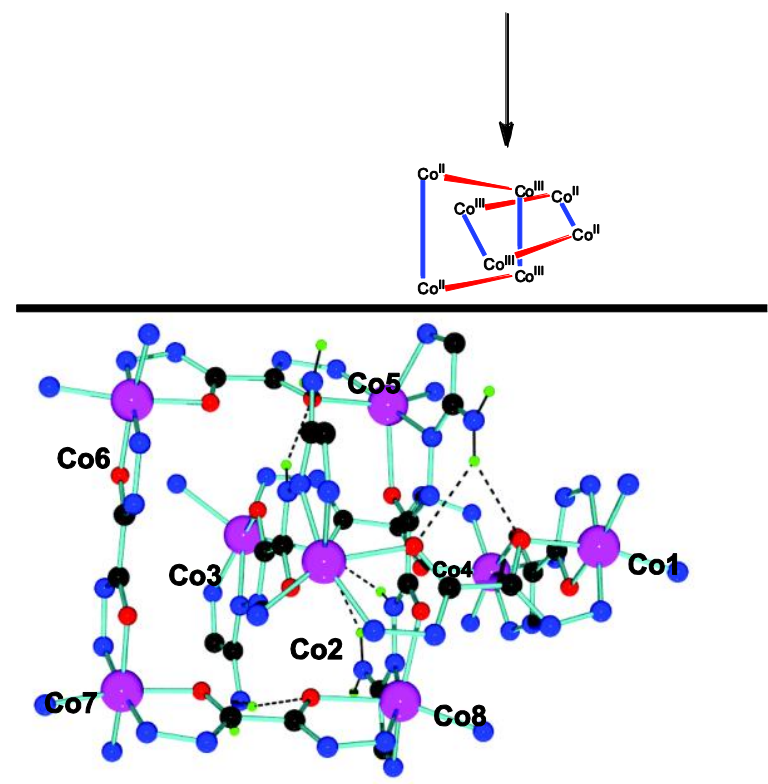

Figure 6. Top) Catenated [2x2] metallogrids formed from ligand 18 with $2 \mathrm{Co}(\mathrm{II})$ ions and $2 \mathrm{Co}$ (III) ions (adapted from the literature ${ }^{122}$ ). Bottom) The X-ray crystal structure of the catenated [2x2] metallogrids. ${ }^{122}$ 


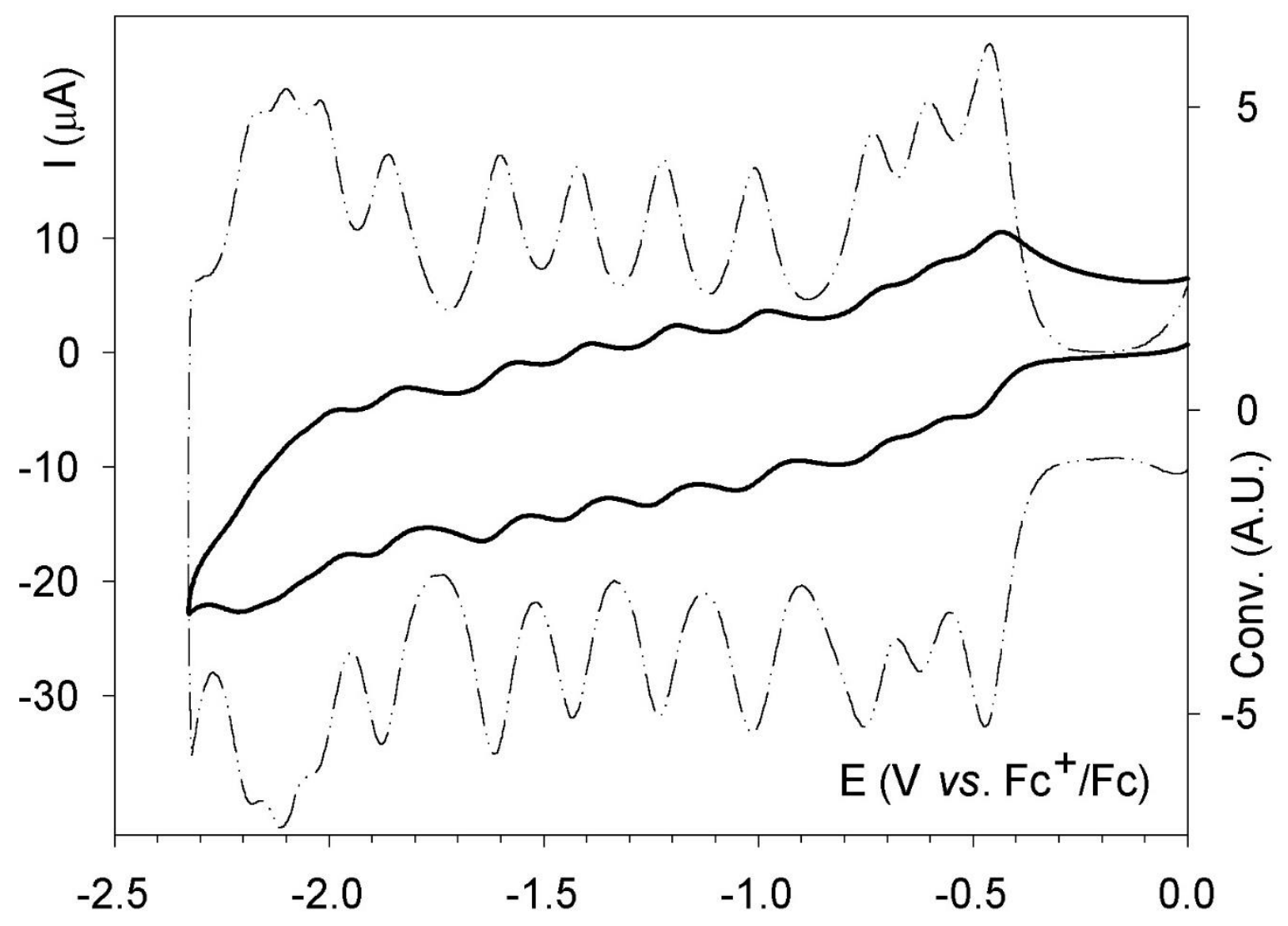

Figure 7. Cyclic voltammetry (bold: scan rate $=0.1 \mathrm{~V} / \mathrm{s}$ ) and its semi-derivative deconvolution (thin) of the [2x2] $\mathrm{Co}$ (II) metallogrid formed from ligand 21 and $0.1 \mathrm{M} \mathrm{Bu}_{4} \mathrm{NPF}_{6}$ in $\mathrm{DMF}$ solution.

Reproduced with the permission of the publisher. ${ }^{125}$ 
<smiles>c1ccc(-c2nc(-c3ccccn3)cc(-c3cccc(-c4ccccn4)n3)n2)cc1</smiles>

23<smiles>[Z4][X]=N/N=C(\C)c1ccccn1</smiles><smiles>Cc1cc(/C(O)=N/N=C(\N)c2ccccn2)n[nH]1</smiles>

25<smiles>C/C(=N\N=C(/O)c1cc(C)[nH]n1)c1ccccn1</smiles>

26

Figure 8. Ligands 23-26 employed in the preparation of metallogrids.

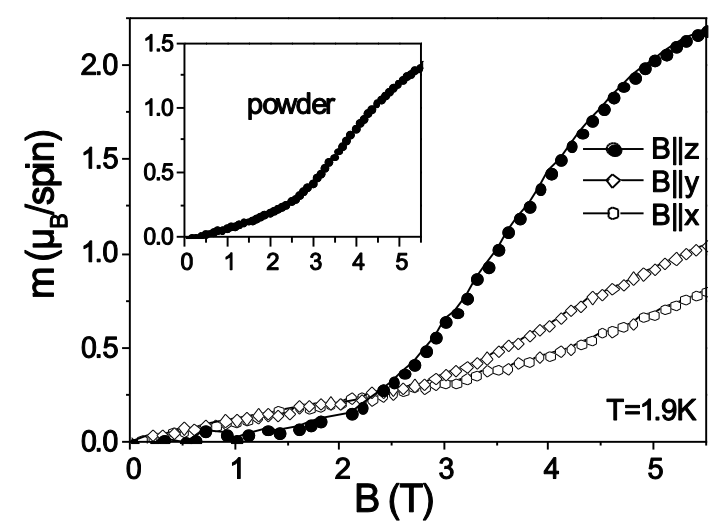

${ }_{5}$ Figure 9. Field dependence of the magnetic moment of a single crystal of [2x2] Co(II) metallogrids formed from ligand $\mathbf{2 1}$ at $1.9 \mathrm{~K}$, for magnetic fields along the main axes. The inset shows the magnetic moment versus field for a powder sample of the same metallogrid. Reproduced with the permission of the publisher. ${ }^{136}$ 


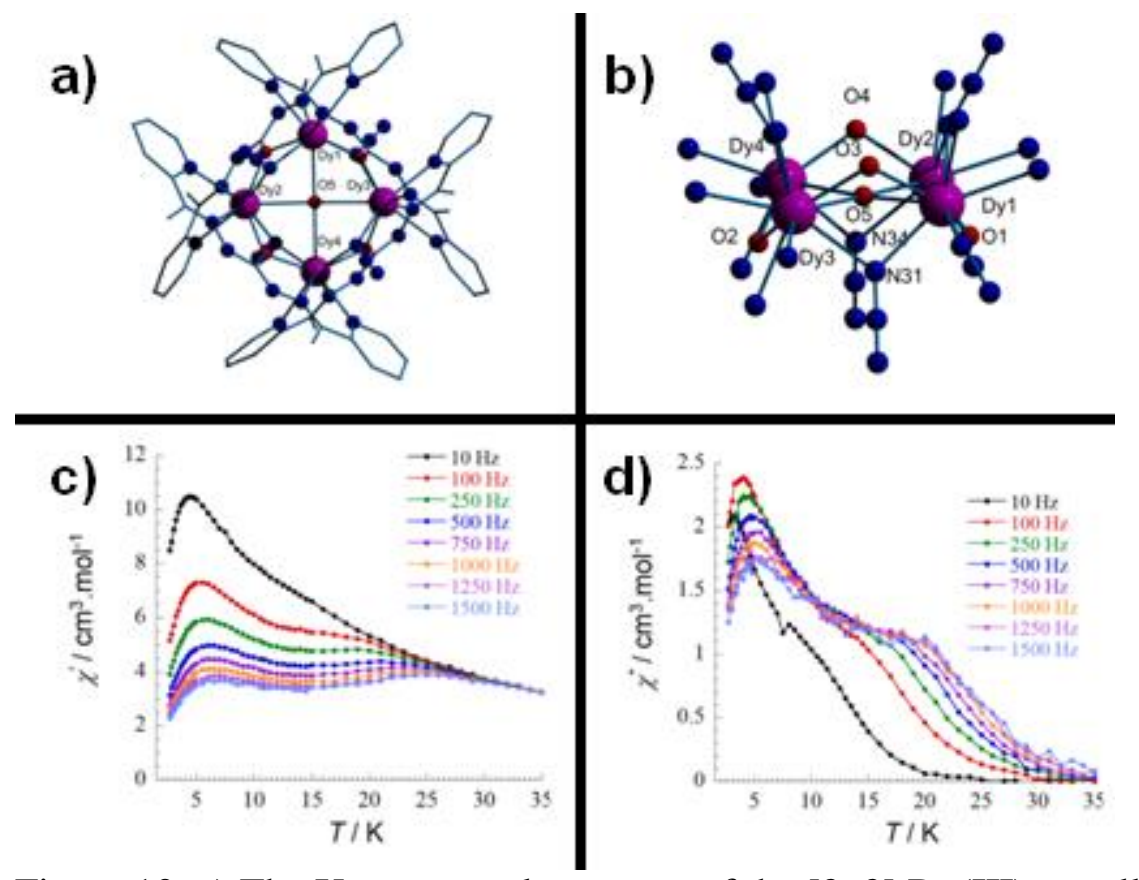

Figure 10. a) The X-ray crystal structure of the [2x2] Dy(III) metallogrids formed from ligand 24. b) the core dimensions. Temperature dependence of the in-phase $\chi^{\prime}$ (c) and out-of-phase $\chi^{\prime \prime}$ (d) AC susceptibility signals for the metallogrids in zero applied field. ${ }^{187}$<smiles>CN(/C=N/c1c[nH]cn1)c1cc(N(C)/N=C/c2cn(N)cn2)nc(-c2ccccc2)n1</smiles>

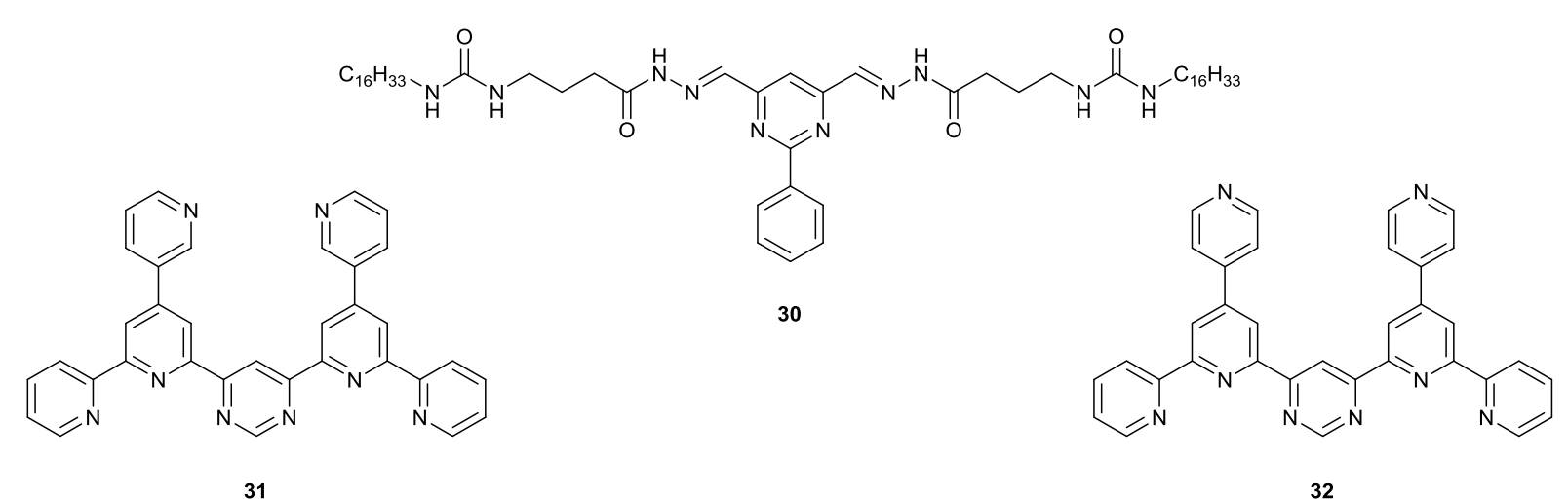

Figure 11. Ligands 27-32 employed in the preparation of metallogrids. 


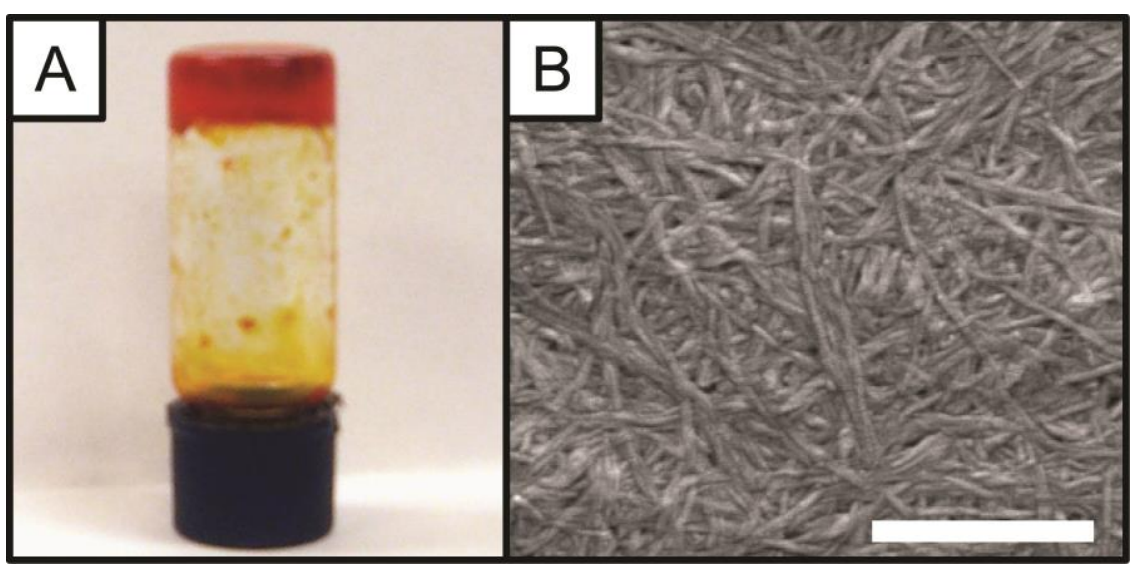

Figure 12. A) Photograph of a metallosupramolecular polymer organogels formed via the hierarchical assembly of [2x2] $\mathrm{Zn}$ (II) metallogrids formed from ligand 30 at a concentration of $20 \mathrm{mg} / \mathrm{ml}$ in toluene. B) SEM image of a dried sample of the same organogels (scale bar represents $1000 \mathrm{~nm}$ ). ${ }^{94}$

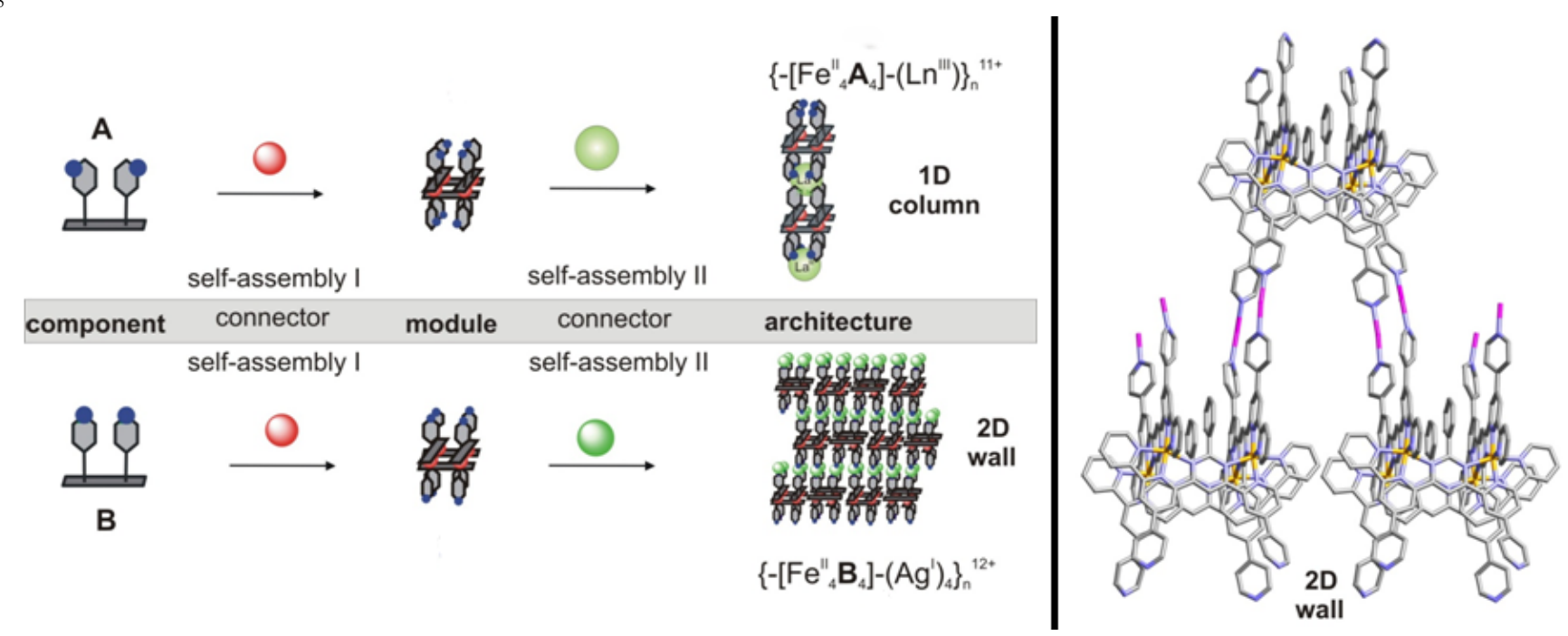

Figure 13. Left) Two-step hierarchical self-assembly of metallosupramolecular architectures with the emergence of magnetic properties. From non-magnetic ligands A (31) and B (32) to the magnetic [2x2] $\mathrm{Fe}(\mathrm{II})$ metallogrids, and their further assembly in the presence of metal ions into of one ${ }_{10}$ dimensional chains or two dimensional arrays of metallogrids (in the presence of $\mathrm{La}(\mathrm{III})$ or $\mathrm{Ag}(\mathrm{I})$ ions respectively). Blue spheres indicate the position of the nitrogen on the pyridine substituents relative to the plane of the metallogrids. Red spheres: Fe(II). Green spheres: top, La(III); bottom, Ag(I). Right) The X-ray crystal structure of two dimensional arrays of [2x2] Fe(II) metallogrids composed of 32 in the presence of $\operatorname{Ag}(\mathrm{I})$ ions. Reproduced with the permission of the publisher. ${ }^{147}$ 
<smiles>Cc1nc(-c2ccccn2)cc(-c2cccc(-c3ccccn3)n2)n1</smiles>

33<smiles>Cc1cccc(-c2ccc(-c3ccc(-c4cccc(C)n4)nn3)nn2)n1</smiles>

34

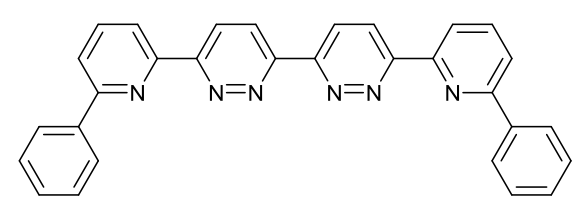

35<smiles>Cc1ccc(-c2cccc(-c3cc(-c4cccc(-c5cccc(-c6cccc(-c7cccc(-c8ccc(CO)cn8)n7)n6)n5)n4)ncn3)n2)nc1</smiles>

36

37

38<smiles>NC(=NN=C(O)c1cc(S)cc(C(O)=NN=C(O)c2cc(Cl)cc(C(O)=NN=C(N)c3ccccn3)n2)n1)c1ccccn1</smiles>

39

40

41<smiles>CCSc1cc(C(O)=NN=C(N)c2ccccn2)nc(C(O)=NN=C(N)c2ccccn2)c1</smiles>

42<smiles>N/C(=N\N=C(O)/C(=N/N=C(\O)c1cccc(C(O)=N/N=C(C(/O)=N\N=C(/N)c2ccccn2)\c2ccccc2)n1)c1ccccc1)c1ccccn1</smiles><smiles>CCCCCCCCCOCc1ccc(-c2cccc(-c3cc(-c4cccc(-c5ccc(COCCCCCCC)cn5)n4)nc(-c4ccccc4)n3)n2)nc1</smiles>

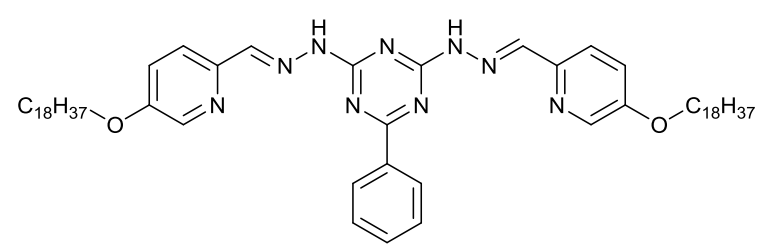

47

Figure 14. Ligands 33-48 employed in the preparation of metallogrids. 


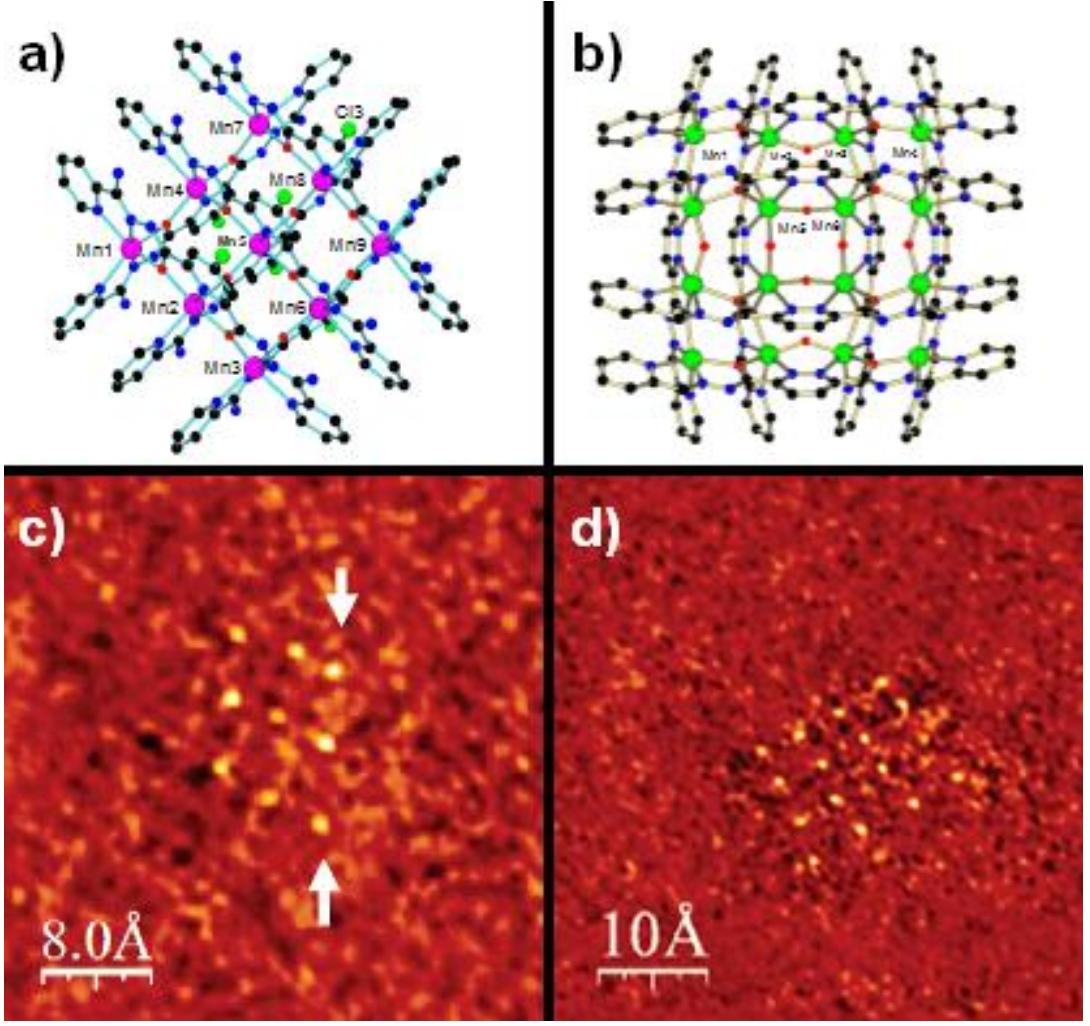

Figure 15. A) The X-ray crystal structure of the [3x3] Mn(II) metallogrid formed from ligand 40. B) The X-ray crystal structure of the [4x4] Mn(II) metallogrid formed from ligand 44. C) A CITS image of a [3x3] Mn(II) metallogrid formed from ligand 40. D) A CITS image of a [4x4] Mn(II) ${ }_{5}$ metallogrid formed from ligand 44. Reproduced with the permission of the publisher. ${ }^{90}$ 


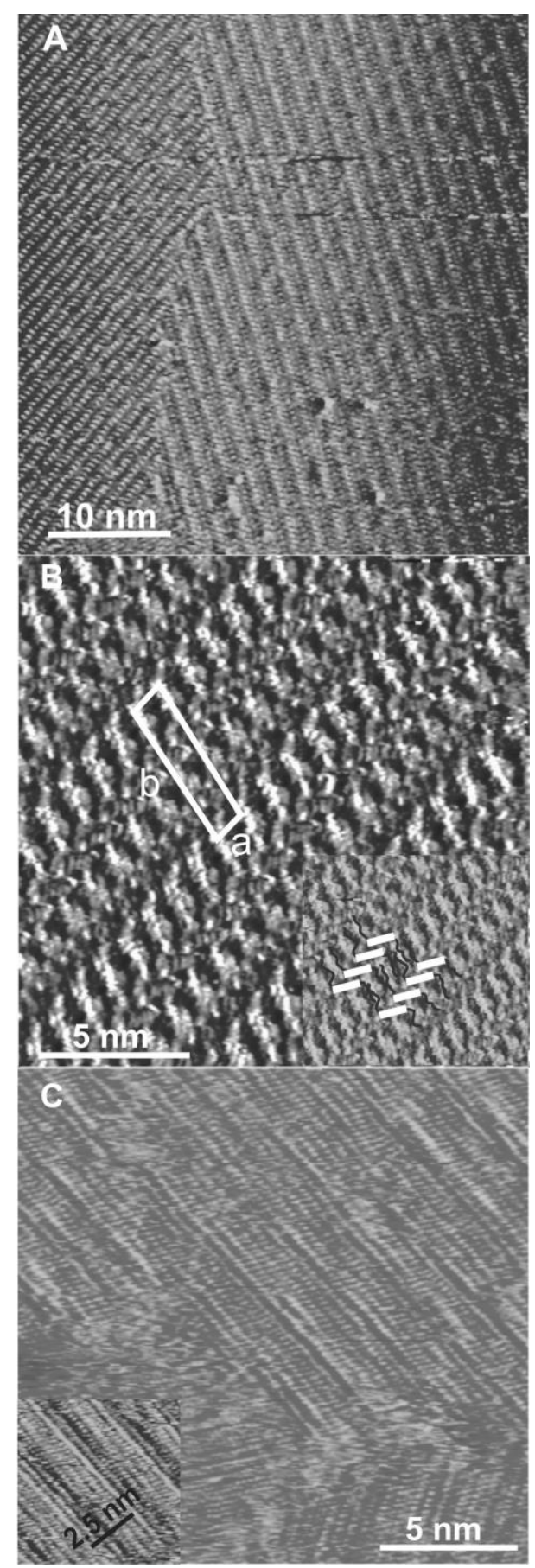

Figure 16. A, B) STM current images of the [2x2] Co(II) metallogrids formed from ligand 48 assembled on a graphite substrate via drop casting at room temperature. Unit cell parameters: $a=1.2$, $b=5.1 \mathrm{~nm} ; \alpha=70^{\circ}$. The unit cell has been corrected for thermal drift. Average tunnelling current, $I_{\mathrm{t}}=35$ ${ }_{s} \mathrm{pA}$; bias voltage, $V_{\mathrm{t}}=583.3 \mathrm{mV}$. The inset of (B) shows the proposed edge-on packing of the metallogrids on the surface; for simplicity not all the alkyl chains have been drawn. C) STM image of the metallogrid assembled under annealing conditions. Inset: magnified image. Reproduced with the permission of the publisher. ${ }^{166}$ 

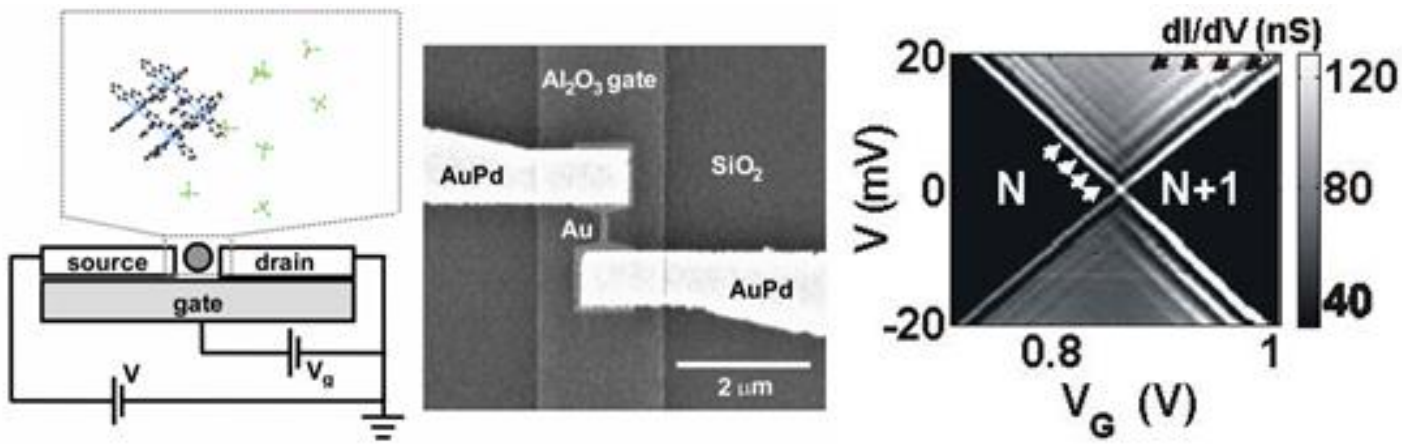

Figure 17. Left) A schematic representation of the device layout used for conductance measurements, with a representation of the cationic $\mathrm{Co}$ (II) metallogrid formed from ligand $\mathbf{2 3}$ as determined by X-ray analysis, shown surrounded by a cloud of $\mathrm{BF}_{4}{ }^{-}$counterions. Middle) An SEM image of a fabricated ${ }_{5}$ device prior to breaking the small gold wire in the middle. Right) A plot of the differential conductance as a function of bias and gate voltage. Regions of high conductance (white and grey), where transport takes place through sequential electron tunnelling are separated by slanted lines from regions of zero conductance (black) due to Coulomb blockade. Reproduced with the permission of the publisher. ${ }^{174}$
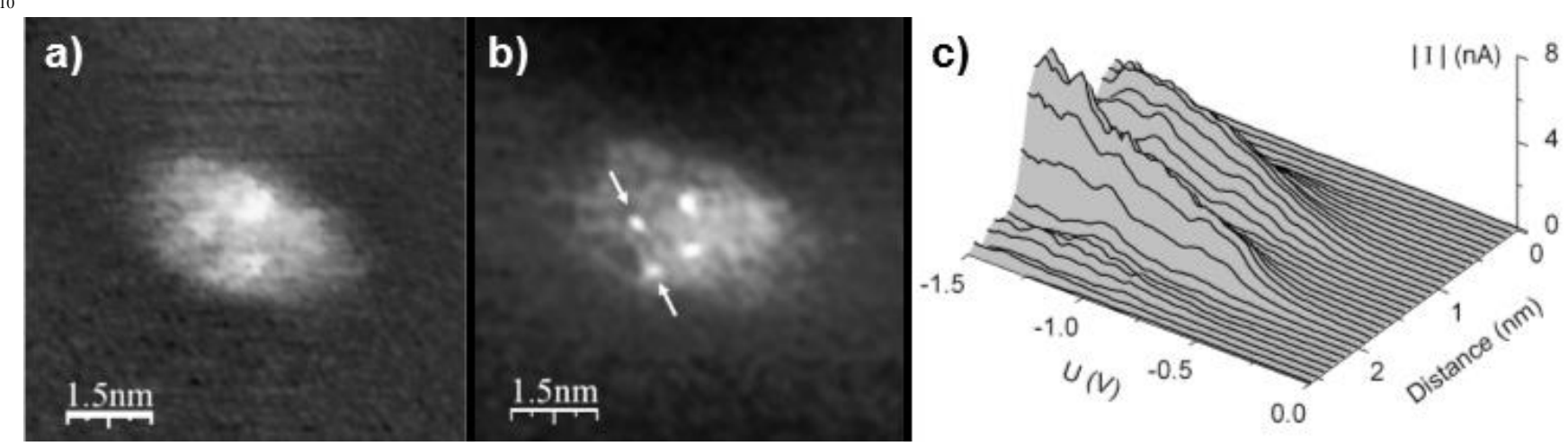

Figure 18. A) A topographic map of a [2x2] Co(II) metallogrid formed from ligand 23. B) A simultaneously recorded CITS image of the same metallogrid. C) A 3D representation of a set of I-V characteristics measured at positions between the two arrows in B. Reproduced with the permission of ${ }_{5}$ the publisher. ${ }^{80}$ 
<smiles>Oc1nc(-c2ccccn2)cc(-c2cccc(-c3ccccn3)n2)n1</smiles>

49<smiles>O=C(N/N=C(\c1ccccc1)c1ccccn1)N/N=C(\c1ccccc1)c1ccccn1</smiles>

50<smiles>CC(=NN=C(O)NN=C(C)c1ccccn1)c1ccccn1</smiles><smiles>c1ccc(-c2cccc(-c3cc(-c4cccc(-c5ccccn5)n4)[nH]n3)n2)nc1</smiles><smiles>C/C(=N\NC(=O)c1cccc(C(=O)N/N=C(\C)c2ccccn2)c1)c1ccccn1</smiles><smiles>CC(=O)NC(C)C(=O)N/N=C/c1cc(/C=N/NC(=O)C(C)NC(C)=O)nc(-c2ccccc2)n1</smiles><smiles>C[N+](C)(C)CC(=O)N/N=C/c1cc(/C=N/NC(=O)C[N+](C)(C)C)nc(-c2ccccc2)n1</smiles>

55

Figure 19. Ligands 49-55 employed in the preparation of metallogrids. 


\section{A}

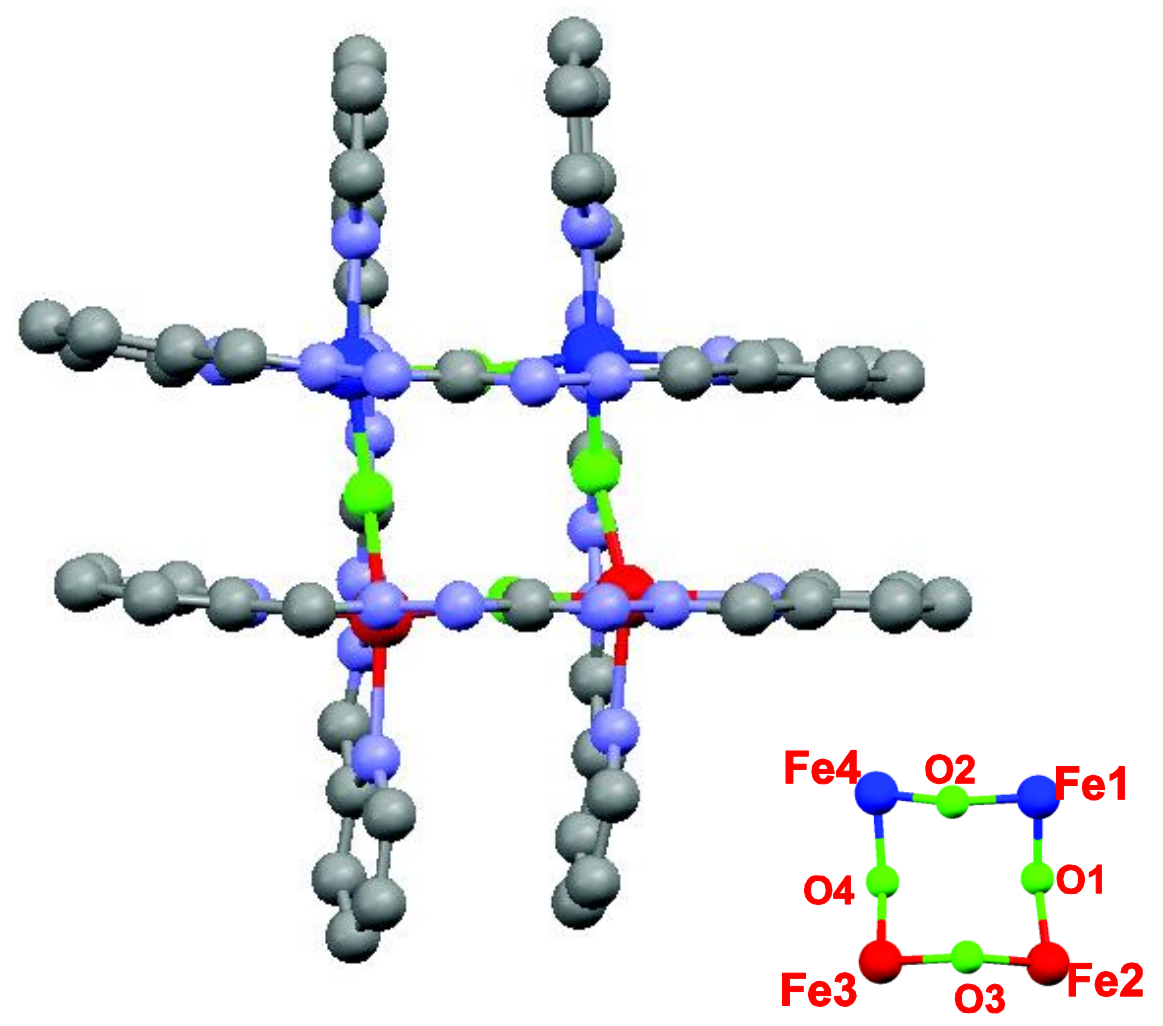

B

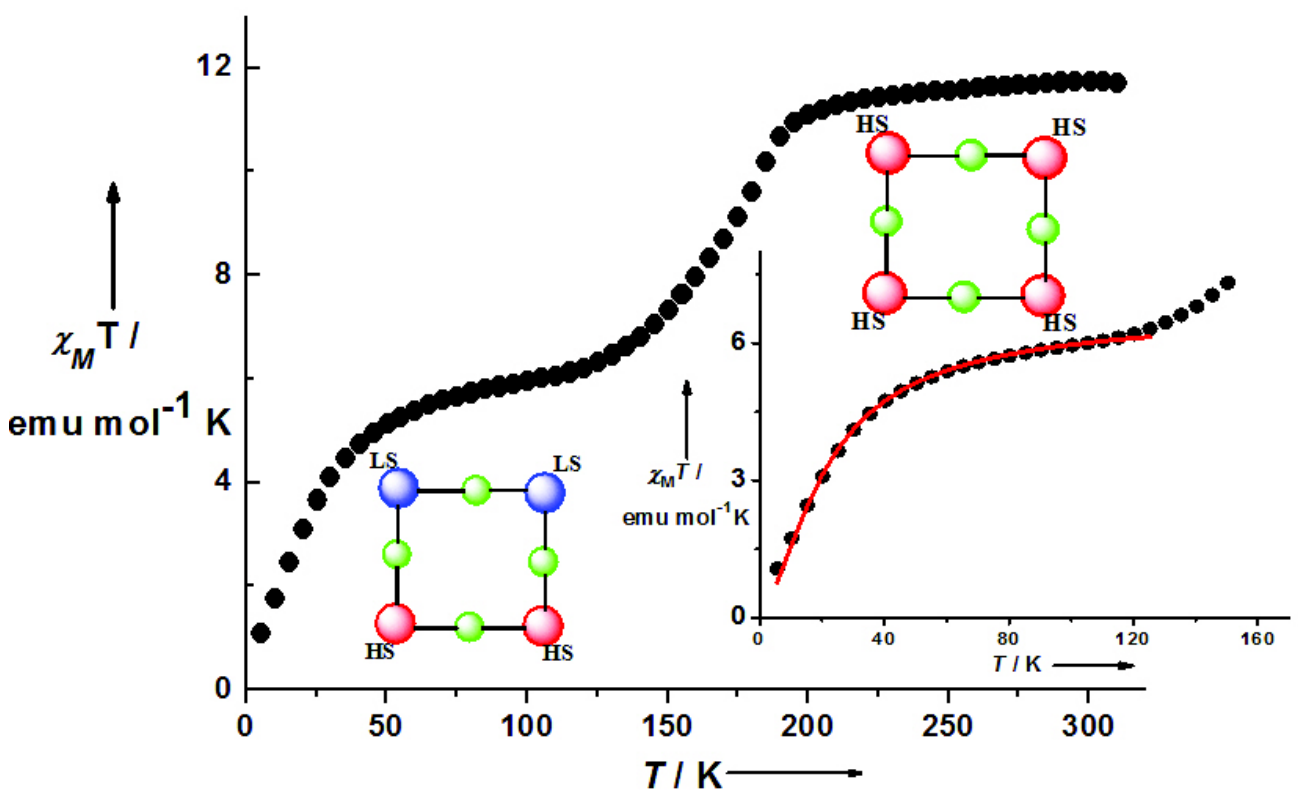

Figure 20. A) The X-ray crystal structure of the [2×2] Fe(II) metallogrid formed from ligand 49, and inset, the structure of the core. B) Evidence of spin crossover behaviour in the $\chi_{\mathrm{M}} \mathrm{T}$ vs T plot for cationic [2x2] $\mathrm{Fe}$ (II) metallogrids formed from ligand 49 in the presence of four tetrafluoroborate ${ }_{5}$ counterions. Inset: Expansion of the data below $150 \mathrm{~K}$, in which the red line represents the best theoretical fit to the experimental data below $120 \mathrm{~K}$. Reproduced with the permission of the publisher. ${ }^{175}$ 

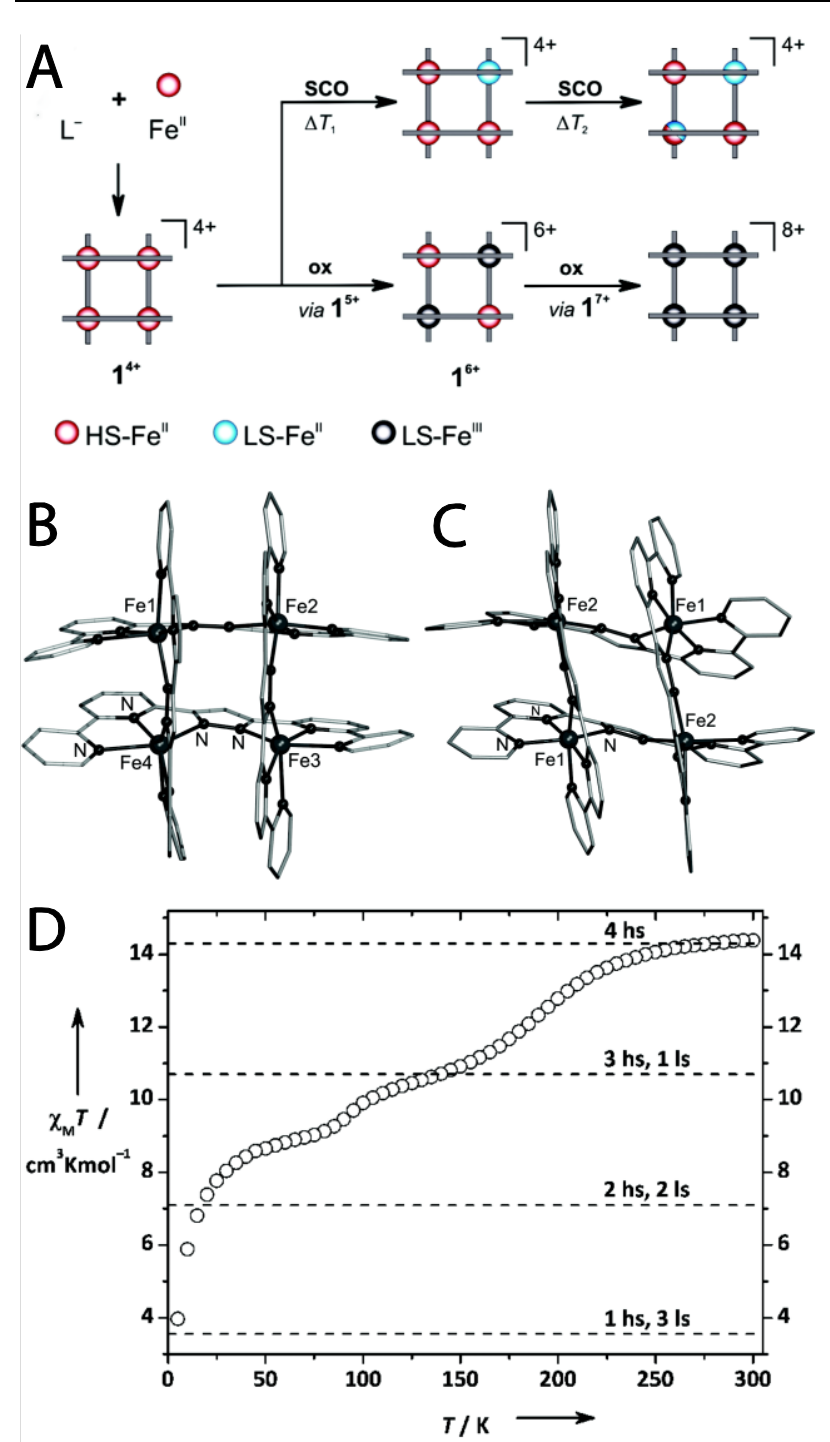

Figure 21. A) An overview of the chemical and physical triggers underlying the spin crossover behaviour displayed by the [2x2] Fe(II) metallogrids formed from ligand 52. B) The X-ray crystal structure of the [2x2] Fe(II) metallogrid formed from ligand $\mathbf{5 2}$ in the ${ }^{4+}$ state. C) The X-ray crystal ${ }_{5}$ structure of the [2x2] Fe(II) metallogrid formed from ligand $\mathbf{5 2}$ in the ${ }^{6+}$ state. D) $\chi_{\mathrm{MT}} \mathrm{vs}$ T plot for the same metallogrids. Reproduced with the permission of the publisher. ${ }^{109}$
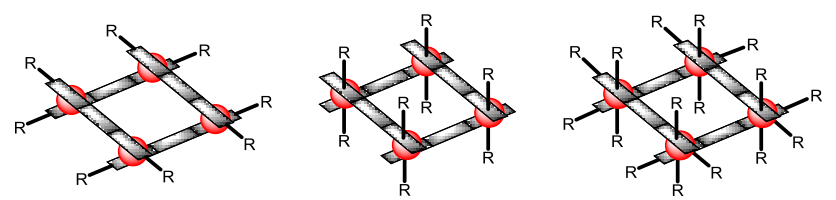

Figure 22. A schematic illustrating 'multivalent' [2x2] metallogrids displaying a specific number of ${ }_{10}$ substituents ( $\mathrm{R}$ groups) with well-defined orientations relative to the plane of the metallogrid, in which the ligands are black and the metal ions are represented by red spheres. Left) 8 substituents are all displayed laterally. Middle) 8 substituents are all displayed axially. Right) 8 substituents are displayed laterally and 8 substituents are all displayed axially. 


\section{Profile}

${ }_{10}$ John Hardy completed his undergraduate studies at the University of Bristol, carrying out undergraduate research in the laboratory of Prof. Brian Vincent. He carried out his doctoral studies at the University of York in the laboratory of Prof. David Smith. He was a postdoctoral fellow in the laboratories of Prof. Jean-Marie Lehn at the University of Strasbourg, and of Prof. Thomas Scheibel at the University of Bayreuth. He moved to the United States to become a postdoctoral fellow in the ${ }_{15}$ laboratory of Prof. Christine Schmidt, first at the University of Texas in Austin and currently at the University of Florida in Gainesville. In the laboratories of each of his different mentors he has enjoyed developing research interests in various aspects of materials chemistry, polymer chemistry, supramolecular chemistry and biomaterials.

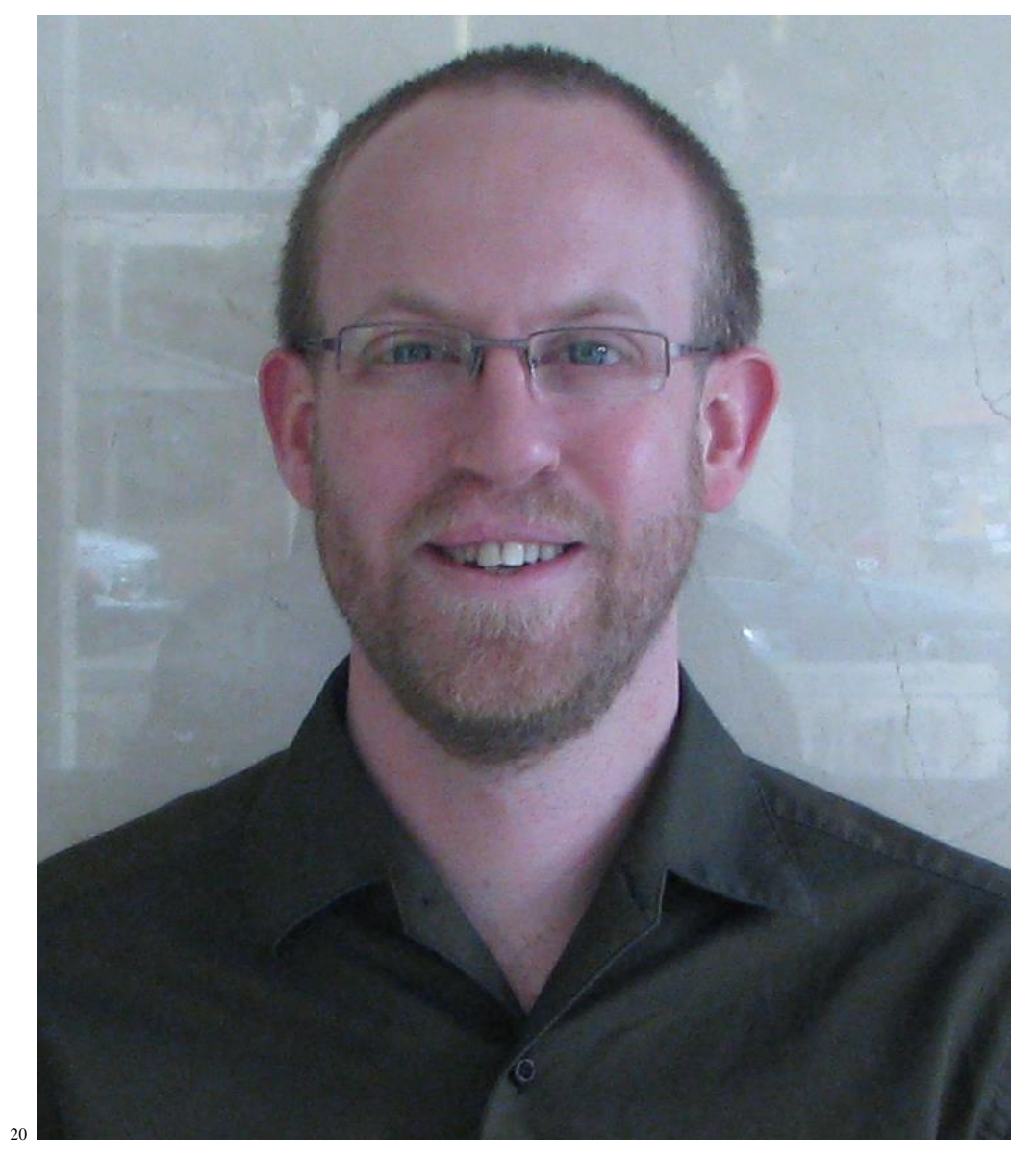

